\title{
Clinical Applications of PET in Brain Tumors*
}

\author{
Wei Chen \\ Department of Molecular and Medical Pharmacology, David Geffen School of Medicine, UCLA, Los Angeles, California; and \\ Department of Radiology, Kaiser Permanente Woodland Hills Medical Center, Woodland Hills, California
}

\begin{abstract}
Malignant gliomas and metastatic tumors are the most common brain tumors. Neuroimaging plays a significant role clinically. In low-grade tumors, neuroimaging is needed to evaluate recurrent disease and to monitor anaplastic transformation into high-grade tumors. In high-grade and metastatic tumors, the imaging challenge is to distinguish between recurrent tumor and treatmentinduced changes such as radiation necrosis. The current clinical gold standard, MRI, provides superior structural detail but poor specificity in identifying viable tumors in brain treated with surgery, radiation, or chemotherapy. ${ }^{18} \mathrm{~F}$-FDG PET identifies anaplastic transformation and has prognostic value. The sensitivity and specificity of ${ }^{18} \mathrm{~F}-\mathrm{FDG}$ in evaluating recurrent tumor and treatment-induced changes can be improved significantly by coregistration with MRI and potentially by delayed imaging 3-8 $\mathrm{h}$ after injection. Amino acid PET tracers are more sensitive than ${ }^{18} \mathrm{~F}-\mathrm{FDG}$ in imaging recurrent tumors and in particular recurrent low-grade tumors. They are also promising in differentiating between recurrent tumors and treatment-induced changes.
\end{abstract}

Key Words: neurology; oncology; PET; brain; tumors

J Nucl Med 2007; 48:1468-1481

DOI: 10.2967/jnumed.106.037689

$\mathbf{M}$ alignant brain tumors are a heterogeneous group of diseases, each with its own biology, prognosis, and treatment. The most common tumor types are metastatic tumors and malignant gliomas. The American Cancer Society estimated that, in 2005, primary brain tumors were the cause of death of approximately 12,760 people. Metastatic tumors are more common; more than 100,000 people die per year with symptomatic intracranial metastases (1). The initial presentation and diagnostic approaches are similar, but the natural courses of disease are different. This article focuses on PET with ${ }^{18} \mathrm{~F}-\mathrm{FDG}$ and ${ }^{18} \mathrm{~F}$-labeled amino acid tracers in malignant gliomas and metastatic tumors, with a special focus on radiation necrosis, tumor recurrence, and

Received Jan. 31, 2007; revision accepted Apr. 19, 2007.

For correspondence or reprints contact: Wei Chen, MD, PhD, CHS, AR-144, David Geffen School of Medicine, UCLA, Los Angeles, CA 90095.

E-mail: weichen@mednet.ucla.edu

Guest Editor: $\mathrm{H}$. William Strauss, Memorial Sloan-Kettering Cancer Center *NOTE: FOR CE CREDIT, YOU CAN ACCESS THIS ACTIVITY THROUGH THE SNM WEB SITE (http://www.snm.org/ce_online) THROUGH SEPTEMBER 2008.

No potential conflict of interest relevant to this article was reported.

COPYRIGHT @ 2007 by the Society of Nuclear Medicine, Inc.
PET-guided biopsy. The article discusses the clinical course and treatment of the tumors; clinical issues pertinent to neuroimaging; the benefits and limitations of the current gold standard, MRI; the role of the established PET tracer ${ }^{18} \mathrm{~F}-\mathrm{FDG}$; and the potential of PET tracers alternative to ${ }^{18} \mathrm{~F}-\mathrm{FDG}$, such as amino acid tracers, with emphasis on ${ }^{18} \mathrm{~F}-$ labeled amino acid tracers.

\section{EPIDEMIOLOGY AND CLASSIFICATION OF GLIOMAS}

According to the classification of the World Health Organization (WHO), gliomas are of 3 main types-astrocytomas, oligodendrogliomas, and mixed oligoastrocytomas-which can usually be distinguished by their histologic features (2). These tumors are typically heterogeneous in that different levels of malignant degeneration can occur in different regions within the same tumor. Analysis of the most malignant region of the tumors establishes grading: low-grade, or WHO grades I and II, and high-grade, or WHO grades III and IV. Grading is based on the degree of nuclear atypia, mitosis, microvascular proliferation, and necrosis, with increasing anaplasia as tumor grade increases. The histologic features of the tumor and the age and performance status of the patient are major prognostic factors on outcome (3). There are 3 subtypes of low-grade gliomas: pilocytic astrocytoma (grade I), astrocytoma (grade II), and oligodendroglioma (grade II). High-grade gliomas include anaplastic tumors (astrocytoma and oligodendroglioma, grade III) and glioblastoma (grade IV). Glioblastoma is the most malignant and most common glioma, accounting for $45 \%-50 \%$ of all gliomas (4). The mean age at onset is $61 \mathrm{y}$ for glioblastoma and $40 \mathrm{y}$ for anaplastic astrocytoma (5). Men are more frequently affected than women, with a sex ratio of 3:2. Low-grade tumors typically affect younger patients than do high-grade gliomas (fourth versus sixth decade of life).

\section{TREATMENT AND OUTCOME}

\section{High-Grade Gliomas}

The clinical course of glioblastoma is usually rapid and fatal, with a median survival of $1 \mathrm{y}$. Median survival for anaplastic tumors is $2-3 \mathrm{y}$.

The treatment for anaplastic astrocytoma and glioblastoma is similar. The current standard of care for newly diagnosed glioblastoma is surgical resection to the extent 
feasible, followed by adjuvant radiotherapy. Maximum resection is important to quickly relieve symptoms and to establish a diagnosis and is associated with lengthened survival and improved neurologic function (6-8). Postoperative radiation has provided a significant survival advantage over surgery alone $(9,10)$. Long-term survival is less than $5 \%$ after surgical resection and radiation or chemotherapy (11). Conventional chemotherapy typically has yielded a response rate of $5 \%-10 \%$ (12). Concurrent radiation with the chemotherapy agent temozolomide has recently been shown to improve survival in patients with newly diagnosed glioblastoma, with a 2 -y survival rate of $26.5 \%$ with radiotherapy plus temozolomide and $10.4 \%$ with radiotherapy alone $(13,14)$.

After the initial treatment, these tumors invariably recur. Patients are treated with a variety of chemotherapeutic agents, and this treatment is an active area of investigation. Patients are followed clinically for neurologic symptoms and through neuroimaging with MRI, the current clinical gold standard. A rapidly enlarging, enhancing lesion on MRI with or without clinical symptoms usually establishes a diagnosis of progressing tumor. However, difficulty with distinguishing between tumor extent and treatment-induced changes such as radiation necrosis limits imaging of the extent of contrast enhancement in malignant gliomas (15). Difficulty also exists in evaluating treatment response with MRI, in that reliable prognostic information often cannot be obtained until many weeks after treatment starts (16).

\section{Low-Grade Gliomas}

Although both grade I and grade II gliomas are classified as low-grade tumors, they are diverse clinically. Grade I tumors such as pilocytic astrocytomas are well-circumscribed contrast-enhancing tumors. They develop mainly in children and young adults. As a rule, pilocytic astrocytomas grow slowly and stabilize spontaneously. Malignant transformation rarely occurs. Surgical resection alone leads to cure or long-term survival in most cases, with $80 \%$ of patients reaching a 20 -y survival. Radiotherapy and possibly chemotherapy are reserved only for unresectable tumors in patients with progressive deficits (17). This article focuses on grade II tumors.

Low-grade gliomas are more indolent than their highgrade counterparts but are associated with significant neurologic disability and are fatal. Reference to these lesions as benign gliomas has generally been abandoned (18). Histologic features of anaplasia, including microscopic endothelial proliferation and necrosis, are absent. Mitotic activity is low. The proliferation index, assessed by MIB-1 antibody targeting the Ki-67 antigen expressed only in proliferative stages of the cell cycle, is generally low at $2 \%-4 \%$ (19). Tumor cells acquire genetic defects that result in anaplastic transformation to a high-grade lesion. At the time of tumor progression, $50 \%-70 \%$ lesions are of high grade $(20,21)$. They may also progress without anaplastic transformation.
Optimal treatment of low-grade gliomas is controversial. Surgery has long been important in their diagnosis and treatment. Surgical resection of the full extent of the tumor is important in establishing an accurate diagnosis, because many tumors are heterogeneous. Recently, in $38 \%$ of 81 patients, a discrepancy was shown between the diagnosis made from small biopsy samples and the diagnosis made from resected specimens (22). Evidence exists that a radical resection may improve symptom control, particularly with regard to seizures (23). However, the impact of the timing and extent of surgery on patient outcome remains the subject of much debate (18). Earlier surgery does not seem to prevent or delay anaplastic transformation, and the effect of surgery on overall survival and progression-free survival is uncertain. Although radiotherapy has played an important part in the management of low-grade glioma, the efficacy and timing of this treatment have also been debated. A recent study of 311 patients demonstrated that radiation after the initial resection may improve progression-free survival but had no effect on overall survival (24).

Astrocytomas and oligodendrogliomas are radiographically indistinguishable, although oligodendrogliomas are more likely to be calcified. Recognition of oligodendrogliomas is important in that oligodendroglioma and, to a lesser extent, mixed oligoastrocytoma carry a better prognosis and greater responsiveness to chemotherapy than does pure astrocytoma $(25,26)$. Oligodendroglial tumors have a more distinct genetic profile than do astrocytomas. Somatic deletions of chromosomes $1 p$ and $19 q$ are the most import events in tumorigenesis, occurring in about $40 \%-70 \%$ of tumors (27). In general, this deletion of $1 p$ and $19 q$ renders tumors more responsive to chemotherapy. The 5-y survival of patients with astrocytomas is around $37 \%$, whereas $70 \%$ of patients with oligodendrogliomas are alive $5 \mathrm{y}$ after diagnosis (28).

The general consensus is that early intervention is preferable in low-grade gliomas when increasing symptoms or radiographic progression is observed, because changes are frequently associated with dedifferentiation to a highergrade tumor (18). Early and adequate tissue sampling is important given the potential for nonenhancing tumors to be anaplastic gliomas rather than low-grade gliomas. Maximal resection is an option in patients whose tumors can be resected. For younger patients who undergo a complete resection, periodic observation with MRI for clinical or radiographic signs of tumor recurrence is a viable option. Radiotherapy is recommended for older patients, especially if total resection is not possible. Chemotherapy is also an option, particularly for patients whose tumors harbor $1 \mathrm{p} /$ $19 \mathrm{q}$ deletion.

\section{Intracranial Metastasis}

Cerebral metastases remain a common complication among patients with systemic cancer. The tumor types most likely to metastasize to the brain are lung, breast, and melanoma (29). Median survival for cerebral metastases 
remains less than $1 \mathrm{y}$, with most patients dying from systemic disease. Traditionally, these patients were treated with whole-brain irradiation, because many have multiple lesions. Surgery allows pathologic verification when diagnosis is uncertain. Surgery is indicated in patients with a relatively good performance status and in patients with large, solitary lesions associated with a significant mass effect. In patients who had solitary metastases and were randomized to whole-brain irradiation with or without surgical resection, surgery with whole-brain irradiation showed a survival advantage $(30,31)$. Recently, stereotactic radiosurgery has emerged as an alternative to whole-brain irradiation and surgery, especially in surgically inaccessible lesions. Stereotactic radiosurgery allows the precise delivery of a high dose of radiation to a defined target in a single treatment session. Patients previously treated with radiotherapy can be retreated with stereotactic radiosurgery in the event of tumor progression. Stereotactic radiosurgery can also be used to treat patients with multiple lesions. Comparative studies of surgery and stereotactic radiosurgery have not been performed (29). Stereotactic radiosurgery is well tolerated, but necrosis is a complication that can occur several months later and may mimic tumor recurrence. Chemotherapy and targeted therapy are active areas of investigation for cerebral metastases.

\section{IMAGING MODALITIES}

\section{Conventional Imaging Studies}

The clinical gold standard, MRI, provides excellent anatomic details. Standard T1- and T2-weighted MRI is highly sensitive in determining the size and location of brain tumors, as well as mass effect, edema, hemorrhage, necrosis, and signs of increased intracranial pressure. Most highgrade tumors such as glioblastoma lead to destruction of the blood-brain barrier (BBB), with subsequent leakage of contrast medium. Low-grade tumors usually show no or minimal enhancement. A high-grade glioma normally presents as an irregular hypodense lesion on T1-weighted MRI, with various degrees of contrast enhancement and edema. Ringlike enhancement surrounding irregularly shaped foci of presumed necrosis is suggestive of glioblastoma. However, anaplastic tumors can often present as nonenhancing tumors, and even glioblastoma may present initially as a nonenhancing lesion, especially in older patients. Likewise, some tumors that appear to be of low grade may contain areas of anaplastic tumor. In addition, the low specificity of MRI in distinguishing neoplastic disease from vascular or inflammatory processes can be a problem in some cases.

It is clinically challenging to evaluate disease status with MRI in patients who have been treated. First, treatmentinduced changes such as radiation necrosis can be difficult to distinguish from recurrent tumor $(15,32)$. This issue is becoming clinically more critical now that concurrent chemoradiation and stereotactic radiosurgery are being used more extensively, because both treatments increase the prevalence of necrosis. Second, dexamethasone has been shown to reduce tumor size, as seen on MRI (33). Many glioma patients are under treatment with corticosteroids, and withholding this drug for the purpose of an imaging study would ethically not be feasible. Last, it is challenging with MRI to evaluate recurrent low-grade tumors without anaplastic transformation, because changes on MRI can often be difficult to distinguish from treatment-induced changes.

\section{F-FDG PET}

Imaging of brain tumors with ${ }^{18} \mathrm{~F}-\mathrm{FDG}$ was the first oncologic application of PET (34-36). ${ }^{18} \mathrm{~F}-\mathrm{FDG}$ is actively transported across the BBB into the cell, where it is phosphorylated. ${ }^{18} \mathrm{~F}$-FDG uptake is generally high in high-grade tumors. The prognostic value of ${ }^{18} \mathrm{~F}$-FDG uptake is well established: High uptake in a previously known low-grade tumor establishes the diagnosis of anaplastic transformation $(37,38)$.

However, recent studies have demonstrated some diagnostic limitations of ${ }^{18}$ F-FDG PET $(39,40)$. Because of the high rate of physiologic glucose metabolism in normal brain tissue, the detectability of tumors with only modest increases in glucose metabolism, such as low-grade tumors and in some cases recurrent high-grade tumors, is difficult. ${ }^{18} \mathrm{~F}$-FDG uptake in low-grade tumors is usually similar to that in normal white matter, and uptake in high-grade tumors can be less than or similar to that in normal gray matter, thus decreasing the sensitivity of lesion detection (Fig. 1). Further, the coupling of ${ }^{18}$ F-FDG uptake and glucose metabolism in tumors can be radically different from that in normal tissue. It was demonstrated that ${ }^{18} \mathrm{~F}$ FDG uptake in tumors could be increased whereas glucose metabolism could not (41). ${ }^{18}$ F-FDG uptake can vary greatly; high-grade tumors may have uptake that is only similar to or slightly above that in white matter, especially after treatment (36).

Coregistration with MRI. Coregistration of ${ }^{18} \mathrm{~F}-\mathrm{FDG}$ PET images with MR images greatly improves the performance of ${ }^{18} \mathrm{~F}$-FDG PET, and it is critical to have the MR images available while the ${ }^{18}$ F-FDG PET images are interpreted (42). Because recurring tumor may show ${ }^{18} \mathrm{~F}$-FDG uptake equal to or lower than uptake in the normal cortex, reference to the
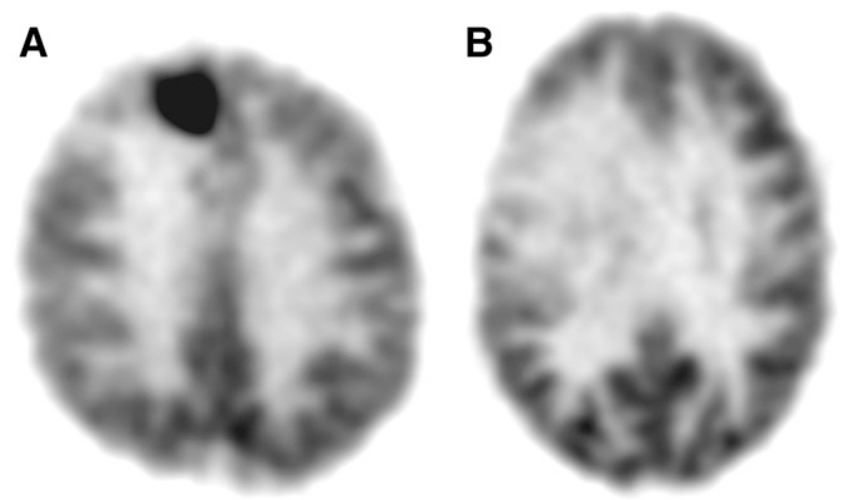

FIGURE 1. ${ }^{18}$ F-FDG PET of newly diagnosed tumors: glioblastoma (A) and grade II oligodendroglioma (B). 
MR image delineates the area of interest. In the area of interest, any ${ }^{18} \mathrm{~F}-\mathrm{FDG}$ uptake higher than the expected background level in the adjacent brain should be considered recurrent tumor if that uptake corresponds to abnormalities on MRI, even though the uptake may be equal to or less than that in normal cortex (Fig. 2).

Delayed Imaging. Early studies reported enhanced detection of brain tumors with glucose loading, with a $27 \%$ increase in the ${ }^{18} \mathrm{~F}-\mathrm{FDG}$ uptake ratio of tumor to normal gray matter (43). However, glucose loading can be difficult to perform clinically because of the need for intravenous glucose infusion and blood glucose monitoring. Recently, an interesting study showed that ${ }^{18} \mathrm{~F}-\mathrm{FDG}$ imaging $3-8 \mathrm{~h}$ after injection can improve the distinction between tumor and normal gray matter (44). The authors hypothesized that glucose excretion from the cells would be increased when the interval between ${ }^{18} \mathrm{~F}-\mathrm{FDG}$ administration and PET data acquisition was extended, that this excretion would be greater in normal brain tissue than in tumor, and that de-
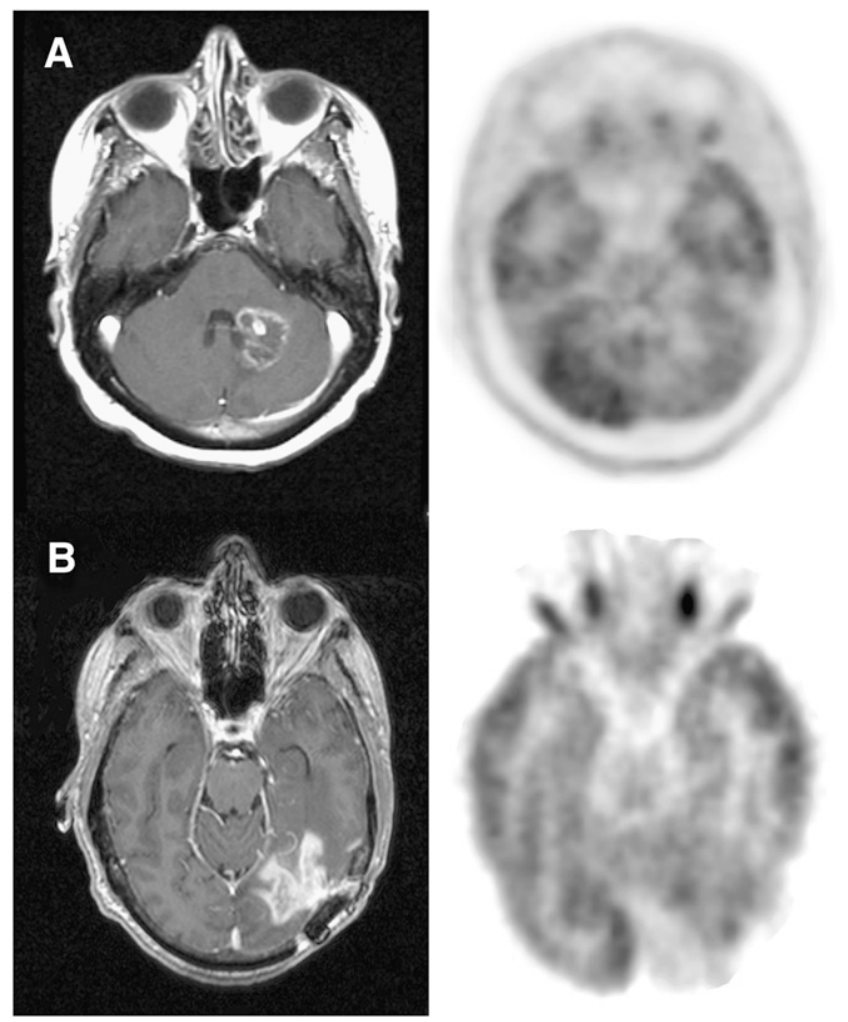

FIGURE 2. Image coregistration of ${ }^{18} \mathrm{~F}-\mathrm{FDG}$ PET and MRI. (A) A 45-y-old woman with radiation necrosis. MRI showed a new contrast-enhancing lesion 4 mo after stereotactic radiosurgery for metastatic breast cancer. ${ }^{18}$ F-FDG PET showed mild uptake not higher than background level of adjacent brain tissue. Radiation necrosis was diagnosed, and MRI lesion regressed during follow-up. (B) A 54-y-old man with recurrent glioblastoma. MRI showed a new contrast-enhancing lesion. ${ }^{18} \mathrm{~F}-\mathrm{FDG}$ PET showed moderate uptake lower than that of normal gray matter but higher than expected background level of adjacent brain tissue and corresponding to abnormal contrast-enhancing region on MRI. Surgery demonstrated recurrent glioblastoma with $\mathrm{Ki}-67$ of $40 \%$. layed imaging might therefore improve the delineation of tumor from normal gray matter. Nineteen patients with gliomas were imaged form 0 to $90 \mathrm{~min}$ and once or twice later at 180-480 min after injection. In 12 of 19 patients, visual analysis of delayed images up to $8 \mathrm{~h}$ after injection showed these images to better distinguish the high uptake in tumors from uptake in gray matter (Fig. 3). Standardized uptake values (SUVs) were also greater in tumors than in normal gray or white matter on delayed imaging. The authors used kinetic modeling to demonstrate that the rate constant of FDG-6-phosphate degradation k4 values was not significantly different between tumor and normal brain tissue at early imaging times but was lower in tumor than in normal brain tissue at delayed times, suggesting that higher FDG-6-phosphate degradation at delayed times may be responsible for higher excretion of ${ }^{18} \mathrm{~F}-\mathrm{FDG}$ from normal tissue than from tumor.

\section{Amino Acid PET Tracers}

Amino acid PET tracers and amino acid analog PET tracers constitute another class of tumor-imaging agents $(45,46)$. They are particularly attractive for imaging brain tumors because of the high uptake in tumor tissue and low uptake in normal brain tissue and, thus, higher tumor-tonormal-tissue contrast. The best-studied amino acid tracer is ${ }^{11} \mathrm{C}$-methionine (47). Because of the short half-life of ${ }^{11} \mathrm{C}$ (20 min), ${ }^{18} \mathrm{~F}$-labeled aromatic amino acid analogs have been developed for tumor imaging (48). Tumor uptake of $O$-(2- ${ }^{18} \mathrm{~F}$-fluoroethyl)-L-tyrosine (FET) and 3,4-dihydroxy$6-{ }^{18} \mathrm{~F}$-fluoro-L-phenylalanine (FDOPA) has been reported to be similar to that of ${ }^{11} \mathrm{C}$-methionine $(49,50)$. The ${ }^{18} \mathrm{~F}-$ FDOPA metabolite 3-O-methyl-6- ${ }^{18} \mathrm{~F}$-fluoro-L-DOPA has also been investigated for brain tumor imaging with PET (51). The diagnostic accuracy of ${ }^{18}$ F-FDOPA was recently reported to be superior to that of ${ }^{18} \mathrm{~F}-\mathrm{FDG}$ in evaluating recurrent low-grade and high-grade gliomas (52).

Amino acids are transported into the cell via carriermediated processes (53). Amino acid imaging is based on the observation that amino acid transport is generally increased in malignant transformation $(54,55)$. In animal models, upregulation of the amino acid transporter in the supporting vasculature of brain tumor tissue has been shown responsible for increased facilitation of amino acid transport into the tumor cell (56). Factors involved in this active transport have been reviewed: flux of the amino acid to the tissue, the intrinsic activity of the amino acid transporter, and the rate of intracellular amino acid metabolism (48). Amino acid transport is generally accepted to be the rate-limiting step, even for the few amino acid tracers that are incorporated into the proteins. The relationship between proliferative activity and amino acid transport was investigated in 3 glioma cell lines (57). The authors elegantly demonstrated, using nonmetabolized amino acid, that increased amino acid transport in tumor cells involves all phases of the cell cycle and that upregulation of amino acid transport ( $\mathrm{L}$ and A systems) occurs in the absence of 
FIGURE 3. A 45-y-old woman with recurrent right temporal glioblastoma. MRI shows contrast enhancement. Tumor-togray matter delineation is more prominent later, at $473 \mathrm{~min}$, than at $90 \mathrm{~min}$. (Adapted from (44).)

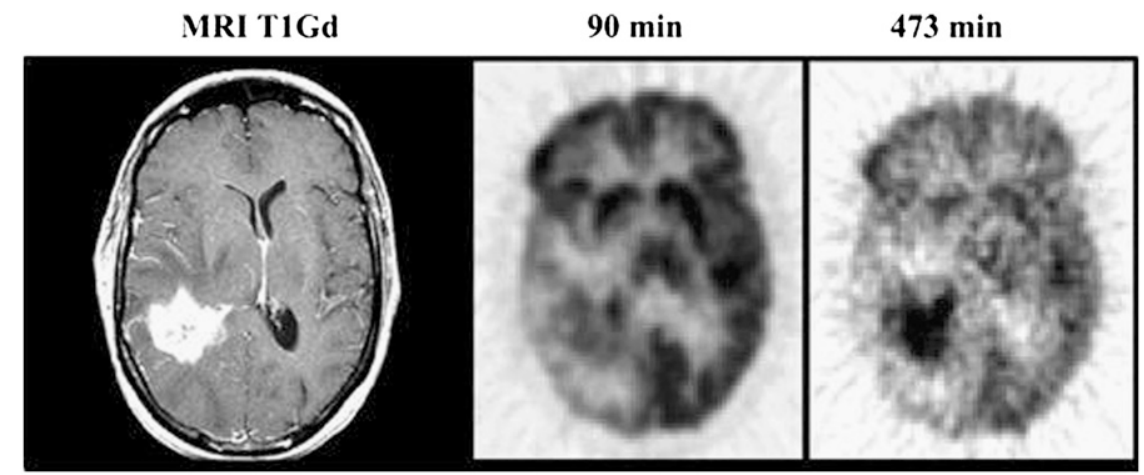

increased vascular permeability. Thus, amino acid transport is increased in tumor cells regardless of the phase of the cell cycle, and this upregulation of transport does not depend on breakdown of the BBB. An earlier study showed that amino acid transport into brain tumors does not depend on, but may be enhanced by, a breakdown in the BBB (58). Uptake of ${ }^{11} \mathrm{C}$-methionine was significant in low-grade astrocytoma but not as high as in glioblastoma. However, ${ }^{11} \mathrm{C}$-methionine uptake was even higher in meningioma (lack of BBB) than in glioblastoma. In contrast, ${ }^{18} \mathrm{~F}-\mathrm{FDG}$ uptake is higher in glioblastoma than in meningioma. Therefore, transport across the $\mathrm{BBB}$ is not the rate-limiting step for ${ }^{18} \mathrm{~F}-\mathrm{FDG}$, whereas transport across the BBB does appear to be the ratelimiting step for amino acid tracers such as ${ }^{11} \mathrm{C}$-methionine. Transport of the ${ }^{18} \mathrm{~F}$-amino acid analog $3-O$-methyl-6- ${ }^{18} \mathrm{~F}-$ fluoro-L-DOPA via sodium-independent, high-capacity amino acid transport systems has been demonstrated in tumor cell lines (59).

\section{EVALUATION OF DISEASE STATUS}

\section{Radiation Necrosis}

The actual incidence of radiation necrosis is not known because few studies have been performed on patients treated with radiation only, and chemotherapy is known to increase the risk of radiation necrosis when both modalities are used (60). Now that stereotactic radiosurgery is used more extensively, and now that it has become standard practice to combine chemotherapy with radiation for highgrade gliomas, the incidence of radiation necrosis is likely to increase. The types of radiation injuries have been reviewed previously (Table 1). Acute injury involves tumor swelling and occurs hours to weeks after the completion of radiation. This type of injury usually is reversible and has a good prognosis. Early delayed injury involves demyelination, occurs weeks to months after the completion of radiation, and also is reversible. Late injury involves liquefactive or coagulative necrosis and usually is irreversible. Late injury can occur months to years after the completion of radiation. The pattern of radiation injury may vary from diffuse periventricular white matter lesions to focal or multifocal lesions. Radiation injury may also occur distant from the original treatment (61). Radiation necrosis is difficult to differentiate from tumor growth on MRI and is especially challenging in early delayed and late injuries because recurring tumor can occur along the same time lines.

${ }^{18} \mathrm{~F}$-FDG PET. Early studies reported that ${ }^{18} \mathrm{~F}$-FDG PET had a sensitivity of $81 \%-86 \%$ and a specificity of $40 \%-$ $94 \%$ for distinguishing between radiation necrosis and tumor (62). In general, methods to define a cutoff SUV were not reliable, because the relative use of glucose and ${ }^{18} \mathrm{~F}$-FDG varied widely for brain tumors and was different from that for normal brain $(41,63)$. Attempts to use the ratio of lesion to contralateral normal white matter or gray matter yielded poor results (40), although this finding was a subject of controversy because another group achieved good results using receiver-operating-characteristic analysis (64). This difficulty with using the ratio approach to diagnose recurrent tumor was due to the fact that an area of treated brain has a wide range of background metabolic activity and usually is of lower metabolic activity than normal untreated brain. Recurring tumors can have a similarly varied degree of metabolic activity that also can frequently

TABLE 1

Characteristics of Radiation Injuries

\begin{tabular}{llll}
\hline Type of injury & Interval after irradiation & \multicolumn{1}{c}{ Pathologic findings } & Prognosis \\
\hline Acute & Hours to weeks & $\begin{array}{l}\text { Tumor swelling } \\
\text { Edema of surrounding brain }\end{array}$ & Good (reversible) \\
Early delayed & Weeks to months & $\begin{array}{l}\text { Demyelination } \\
\text { Liquefactive or coagulative necrosis }\end{array}$ & $\begin{array}{l}\text { Good (spontaneously reversible) } \\
\text { Late }\end{array}$ \\
Months to years & & Clinical severity variable
\end{tabular}

Adapted with permission from (60). 
be lower than that of normal brain. Diagnostic performance appears better in gliomas than in metastatic lesions and is worse in lesions treated with stereotactic radiosurgery $(60)$.

Thus, when one is interpreting ${ }^{18} \mathrm{~F}$-FDG PET images of a treated brain to distinguish recurrent tumor from radiation necrosis, it is critical to evaluate lesion activity not by the absolute uptake value, and not by the ratio to untreated normal brain tissue, but by whether lesion activity is above the expected background activity in adjacent brain tissue. It is also critical to have the MRI structural information available for correlation. In a series of 44 lesions treated with stereotactic radiosurgery, ${ }^{18} \mathrm{~F}-\mathrm{FDG}$ PET alone had a sensitivity of $65 \%$ in subjects with metastases but reached $86 \%$ when MRI and PET images were coregistered (65). Any area of ${ }^{18} \mathrm{~F}$-FDG uptake higher than the expected background activity in adjacent brain tissue was considered suggestive, as was any area of ${ }^{18} \mathrm{~F}-\mathrm{FDG}$ uptake in a region showing contrast enhancement on coregistered MR images (Fig. 2). A series of 117 postradiotherapy patients demonstrated a sensitivity of $96 \%$ and specificity of $77 \%$ in distinguishing recurrent tumor from radiation necrosis when such criteria were used (66).

Much of the wide range of ${ }^{18} \mathrm{~F}$-FDG PET performance in evaluating radiation necrosis may be attributable to differences in the timing of PET after radiation, in the type of radiation, and in the type of tumor. ${ }^{18} \mathrm{~F}$-FDG uptake was shown to vary with the timing after radiation treatment, and overlap of ${ }^{18} \mathrm{~F}$-FDG uptake between radiation necrosis and residual tumor could be considerable (67). The optimal time for performing ${ }^{18} \mathrm{~F}-$ FDG PET after radiation is not known (67). The general recommendation is that, for the purpose of evaluating tumor growth, ${ }^{18} \mathrm{~F}$-FDG PET should not be performed less than $6 \mathrm{wk}$ after the completion of radiation treatment.

A potentially useful approach would be to use delayed imaging, because it apparently enhances the tumor-tonormal-brain uptake ratio (44). An attractive hypothesis is that, like normal brain tissue, necrotic tissue would show greater ${ }^{18} \mathrm{~F}-\mathrm{FDG}$ excretion at delayed times than would tumor. Further studies are needed to evaluate whether this approach can increase diagnostic accuracy in distinguishing radiation necrosis from recurrent tumor.

Other PET Tracers. Because amino acid tracers appear more sensitive than ${ }^{18} \mathrm{~F}-\mathrm{FDG}$ PET in visualizing tumor, they also have potentially better diagnostic performance than ${ }^{18} \mathrm{~F}-$ FDG PET in evaluating radiation necrosis. However, the degree of amino acid uptake in radiation necrosis lesions is not well known. ${ }^{11} \mathrm{C}$-Methionine has been available for $2 \mathrm{de}-$ cades, but few studies have been published on its performance in differentiating radiation necrosis from brain tumor recurrence (60). In a study of 21 patients with brain metastases treated by stereotactic radiosurgery, ${ }^{11} \mathrm{C}$-methionine correctly identified 7 of 9 recurrences and 10 of 12 radiation injuries (68).

In rats, uptake of ${ }^{18} \mathrm{~F}$-FET, ${ }^{18} \mathrm{~F}$-FDG, and ${ }^{18} \mathrm{~F}$-choline has been compared in acute lesions caused by cerebral radiation injury (inflammatory cells) and in acute cryolesions (disruption of BBB) (69). Both ${ }^{18} \mathrm{~F}-\mathrm{FDG}$ and ${ }^{18} \mathrm{~F}$-choline accumulated in macrophages, a common inflammatory mediator in radiation necrosis, but ${ }^{18} \mathrm{~F}$-FET uptake was absent from macrophages. Moreover, the ratio of ${ }^{18} \mathrm{~F}-\mathrm{FET}$ uptake in radiation necrosis to that in normal cortex was much lower than the corresponding ratios for ${ }^{18} \mathrm{~F}-\mathrm{FDG}$ and ${ }^{18} \mathrm{~F}$-choline, suggesting that ${ }^{18} \mathrm{~F}$-FET is promising for differentiating radiation necrosis from tumor recurrence. Absence of ${ }^{18} \mathrm{~F}$ FET uptake in a case of radiation necrosis has been reported (49). In a recently reported study with ${ }^{18}$ F-FDOPA, a lesionto-normal-brain ratio of less than 1.6 and a lesion-to-striatum ratio of less than 1.0 were demonstrated in 4 cases of radiation necrosis (from treatment of metastatic lung cancer, metastatic melanoma, glioblastoma, and grade III astrocytoma) (52). Although these results appear promising, larger systematic studies are needed to evaluate the accuracies of these amino acid tracers in differentiating radiation necrosis from recurrent tumor.

\section{Evaluation of Recurrent Tumors}

${ }^{18} \mathrm{~F}$-FDG PET. High ${ }^{18} \mathrm{~F}$-FDG uptake in a previously diagnosed low-grade glioma with low ${ }^{18} \mathrm{~F}-\mathrm{FDG}$ uptake is diagnostic of anaplastic transformation (Fig. 4). This increase in ${ }^{18} \mathrm{~F}-\mathrm{FDG}$ uptake is strongly prognostic. Twenty-eight patients with low-grade glioma were studied with ${ }^{18} \mathrm{~F}-\mathrm{FDG}$ PET and followed for a mean of 27 mo (38). All 19 patients with tumors that were hypometabolic on PET were alive at the end of the follow-up period, whereas 6 of 9 patients with hypermetabolic patterns on PET had died.

${ }^{18}$ F-FDG PET performs generally well in identifying growing high-grade gliomas. In lesions that are equivocal on MRI, ${ }^{18} \mathrm{~F}-\mathrm{FDG}$ PET may have limited sensitivity (52). ${ }^{18} \mathrm{~F}-\mathrm{FDG}$ PET is generally not sensitive in identifying recurrent lowgrade tumors without anaplastic transformation (Fig. 4).

Amino Acid Tracers. In contrast to ${ }^{18} \mathrm{~F}-\mathrm{FDG}$ uptake, amino acid uptake has been shown to be increased relative to normal brain tissue in most low- and high-grade tumors, and radiolabeled amino acids might therefore be preferable for evaluating recurrent tumors (47). Initial research focused on ${ }^{11} \mathrm{C}$-labeled amino acids, particularly ${ }^{11} \mathrm{C}$-methionine (40). However, because of the short half-life of ${ }^{11} \mathrm{C}$, the applicability of this tracer is limited to facilities with on-site cyclotrons, and the demand for ${ }^{18} \mathrm{~F}$-labeled analogs has been increasing.

The usefulness of ${ }^{11} \mathrm{C}$-methionine PET in 45 brain lesions that did not show increased uptake on ${ }^{18} \mathrm{~F}$-FDG PET was evaluated (70). Thirty-four of these lesions were at the initial presentation, and 11 were being evaluated for recurrence. There were 24 gliomas, 5 metastatic tumors, 4 meningiomas, 2 other brain tumors, and 10 benign lesions. ${ }^{11} \mathrm{C}$-Methionine demonstrated increased uptake in 31 of 35 tumors $(89 \%$ sensitivity). For 24 gliomas, ${ }^{11} \mathrm{C}$-methionine demonstrated positive uptake in 22 (92\% sensitivity). All 10 benign brain lesions (cysticercosis, radiation necrosis, tuberculous granuloma, hemangioma, organized infarction, and benign cyst) showed normal or decreased ${ }^{11} \mathrm{C}$-methionine uptake $(100 \%$

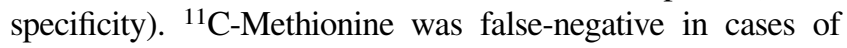
intermediate oligodendroglioma, metastatic tumor, chordoma, and cystic ganglioma. 

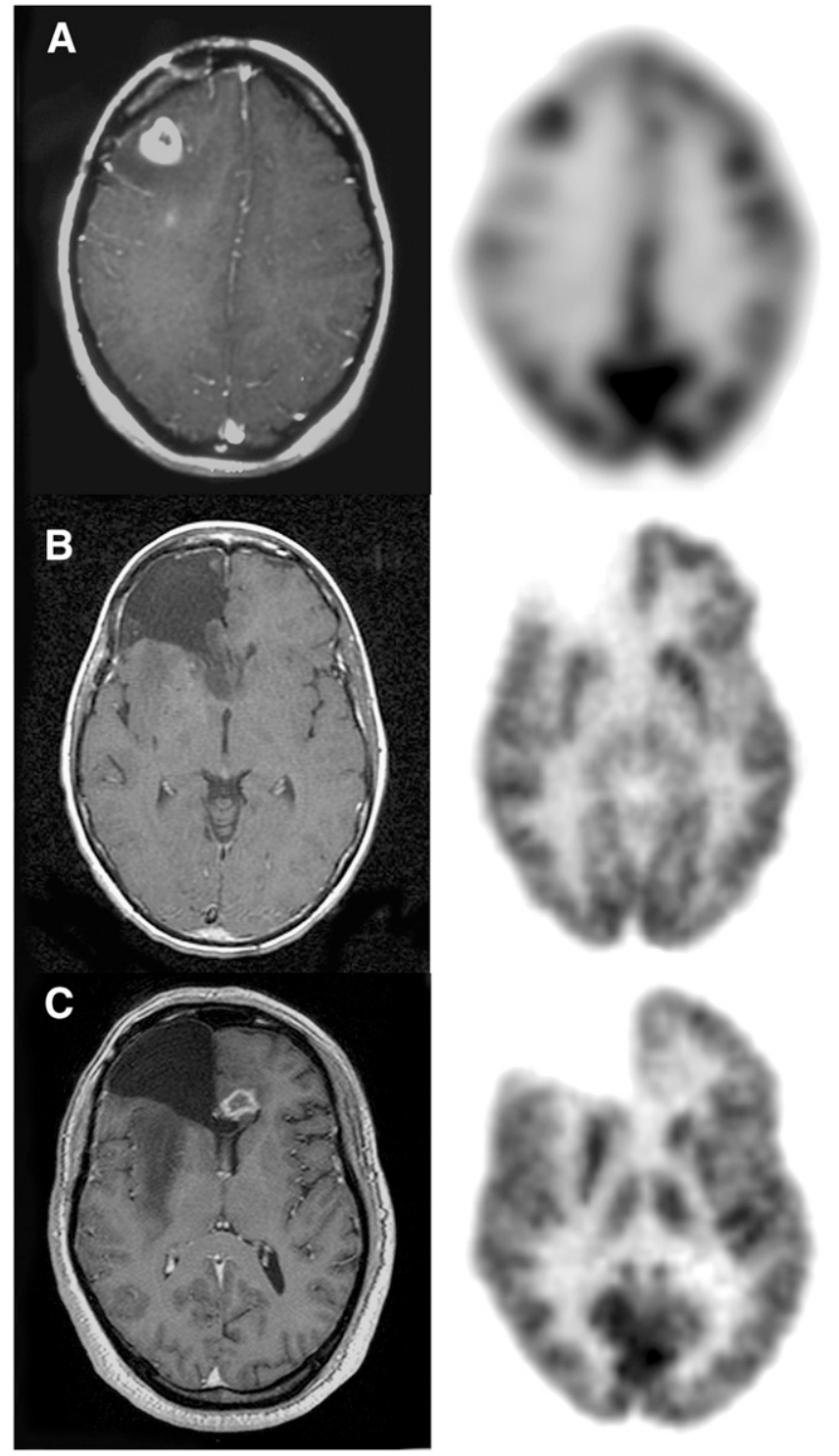

FIGURE 4. $\mathrm{MRI}$ and ${ }^{18} \mathrm{~F}-\mathrm{FDG}$ PET of recurrent tumors. (A) Anaplastic transformation in previously resected and irradiated grade II astrocytoma. Intense ${ }^{18} \mathrm{~F}-\mathrm{FDG}$ uptake corresponds to new contrast-enhancing lesion on MRI. (B) Recurrent grade II oligodendroglioma. No increased ${ }^{18} \mathrm{~F}-\mathrm{FDG}$ uptake is seen. (C) Patient with previously resected and irradiated right frontal grade II astrocytoma. New contrast-enhancing lesion in left frontal lobe corresponds to minimally increased ${ }^{18} \mathrm{~F}-\mathrm{FDG}$ uptake. This lesion was resected, and grade IV tumor was found.

An initial study demonstrated that uptake of ${ }^{18} \mathrm{~F}$-FET in brain tumors is similar to that of ${ }^{11} \mathrm{C}$-methionine (49). The diagnostic value of ${ }^{18} \mathrm{~F}$-FET PET was evaluated in 53 patients with clinically suspected recurrent glioma (71). All patients had gliomas and initially underwent surgery and various additional treatments. Forty-three patients initially had high-grade gliomas and 10 patients had low-grade gliomas. All 42 patients with confirmed recurrent tumors had focally increased ${ }^{18}$ F-FET uptake, whereas only low, homogeneous ${ }^{18} \mathrm{~F}$-FET uptake was seen at the margins of the resection cavity in the 11 patients without recurrence.
Thus, ${ }^{18}$ F-FET was able to distinguish between recurrent tumor and therapy-induced benign changes with $100 \%$ accuracy. In this study, focal and high ${ }^{18} \mathrm{~F}$-FET uptake was considered suggestive of tumor recurrence, whereas low and homogeneous uptake around the resection cavity was considered a benign posttreatment change (Fig. 5). Assuming that the expression of amino acid transporters is upregulated in tumor tissue but not in tissues affected by posttreatment changes, one can attribute increased amino acid uptake into this tissue mainly to treatment-induced disruption of the blood-brain barrier. The best differentiation between benign posttreatment changes and recurrent tumor was found at a threshold of 2.0 for the ratio of maximum SUV to background or a threshold of 2.2 for the absolute maximum SUV. Using the maximum SUV or an $80 \%$ isocontour yielded similar results. The diagnostic accuracy of ${ }^{18} \mathrm{~F}-\mathrm{FET}$ PET and MRI was compared in 45 patients with 34 high-grade and 11 low-grade gliomas (72). ${ }^{18}$ F-FET PET and MRI produced a correct diagnosis in 44 and 36 patients, respectively. When a threshold of 2.2 was used for the maximum SUV, the specificity of ${ }^{18} \mathrm{~F}$-FET PET was $92.9 \%$ and the sensitivity was $100 \%$. The sensitivity of MRI was $93.5 \%$ and the specificity was $50 \% .{ }^{18}$ F-FET PET was concordant with MRI in 37 patients and discordant in 8 patients. The authors cautioned that the high sensitivity and specificity of ${ }^{18}$ F-FET PET may be due to the fact that tumor recurrence was suspected in all patients on the basis of the MRI findings. The authors also suggested that because MRI has high sensitivity but poor specificity, it should be used first, as a screening test. In the event of suspected tumor recurrence, additional ${ }^{18} \mathrm{~F}$-FET PET investigation seems to differentiate between posttreatment changes and tumor recurrence and to avoid both under- and overtreatment.

In general, ${ }^{18} \mathrm{~F}$-FET PET has not been shown useful in differentiating low- from high-grade tumors, although some investigators reported that the kinetic profile in ${ }^{18} \mathrm{~F}$-FET uptake for low- and high-grade tumors might be a useful feature for distinguishing the 2 types of tumors (73).

For many years, ${ }^{18} \mathrm{~F}-\mathrm{FDOPA}$ imaging of the integrity of the striatal dopamine pathway has been used to evaluate patients with movement disorders (74-76). However, ${ }^{18} \mathrm{~F}-$ FDOPA is also an amino acid analog and was shown to be taken up at the BBB in normal brain by the neutral amino acid transporter $(77,78)$. The initial report of ${ }^{18} \mathrm{~F}$-FDOPA imaging of a glioma was as an incidental finding in a patient undergoing evaluation of movement disorders (79). Subsequently, ${ }^{18} \mathrm{~F}$-FDOPA PET and ${ }^{11} \mathrm{C}$-methionine PET of brain tumors were compared in 19 patients (50). No significant difference in uptake between ${ }^{18} \mathrm{~F}$-FDOPA and ${ }^{11} \mathrm{C}$ methionine was found in either low- or high-grade tumors.

The most detailed and comprehensive study of ${ }^{18} \mathrm{~F}$ FDOPA in brain tumors was published last year. ${ }^{18} \mathrm{~F}$-FDOPA was compared with ${ }^{18} \mathrm{~F}-\mathrm{FDG}$ in 30 patients with brain tumors, and the diagnostic accuracy of ${ }^{18} \mathrm{~F}-\mathrm{FDOPA}$ was evaluated in a subsequent expansion of the study to an additional 51 patients (52). Initially, 30 patients with 


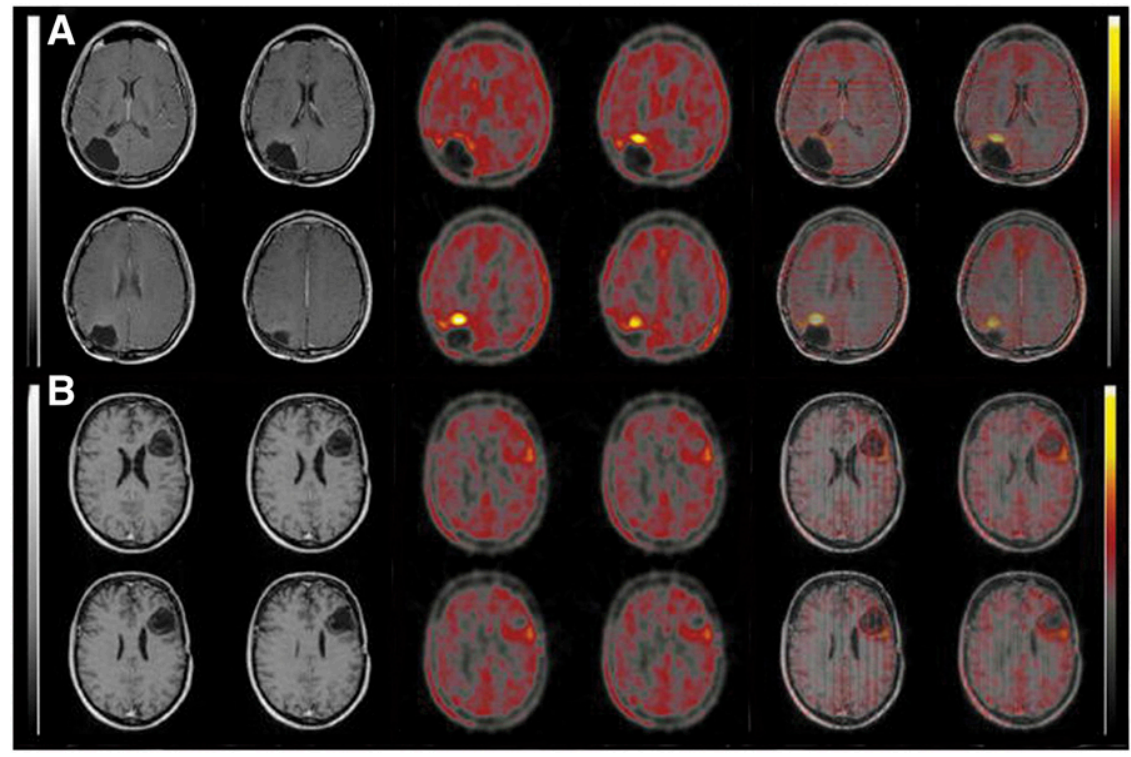

FIGURE 5. MRI, ${ }^{18} \mathrm{~F}-\mathrm{FET}$ PET, and fused images. (A) A 30-y-old man who had undergone initial surgery, radiation therapy, and intralesional radioimmunotherapy for anaplastic astrocytoma. Biopsyproven recurrent tumor (WHO grade IV) occurred 20 mo after initial diagnosis. MRI shows no contrast enhancement and was rated normal. PET shows focal ${ }^{18} \mathrm{~F}-\mathrm{FET}$ uptake. Maximal SUV is 3.0, with ratio of 4.0 to background. (B) A 42-y-old woman who had undergone initial surgery and radiation therapy for WHO II astrocytoma. This patient was proven free of tumor by biopsy 67 mo after initial diagnosis. MRI shows suggestive contrast enhancement at border of cavity, whereas only moderate ${ }^{18} \mathrm{~F}-\mathrm{FET}$ uptake is present on PET. Maximal SUV is 1.7, with ratio of 1.75 to background. (Adapted from Figure 1 of (71) with the kind permission of Springer Science and Business Media.)

brain tumors, newly diagnosed or previously treated, were prospectively studied. The distribution of cases based on the WHO histopathologic classification was as follows: 7 patients had newly diagnosed glioma (3 grade II, 1 grade III, and 3 grade IV), and 23 were previously treated with surgical resection or radiation (original primary tumors: 2 grade II, 3 grade III, and 15 grade IV; metastatic brain tumors: 1 breast, 1 lung, and 1 melanoma). All patients were studied with ${ }^{18}$ F-FDOPA and ${ }^{18}$ F-FDG PET within the same week. MRI studies of the brain were acquired in all patients within $1 \mathrm{wk}$ before the PET scans. The accuracy of the imaging data was validated by histology or subsequent clinical follow-up.
Time-activity curves demonstrated that the highest tracer uptake in tumor and cerebellum generally occurred between 10 and $30 \mathrm{~min}$ after injection. Tracer activity in the striatum did not peak until $50 \mathrm{~min}$ after injection. Thus, tumor uptake from 10 to $30 \mathrm{~min}$ after injection is near maximum and occurs sufficiently early to avoid peak uptake in the striatum.

With the criterion that any tracer activity above the background level of adjacent brain be considered abnormal, 22 of 23 high- and low-grade tumors were visualized with ${ }^{18} \mathrm{~F}-$ FDOPA, with 1 false-negative finding occurring in a patient with residual low-grade tumor (Fig. 6). All 3 patients without active disease (in long-term remission) lacked visible
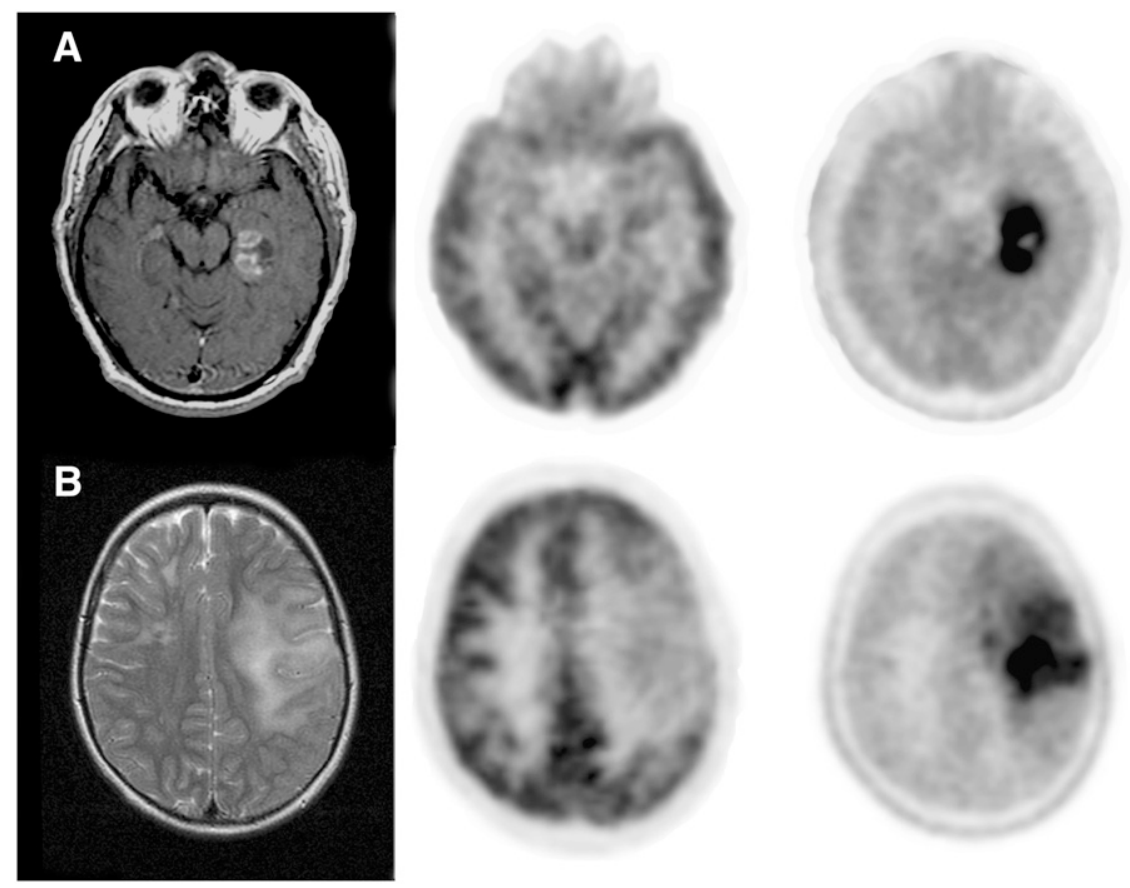

FIGURE 6. MRI, ${ }^{18} \mathrm{~F}-\mathrm{FDG} \mathrm{PET}$, and ${ }^{18} \mathrm{~F}-$ FDOPA PET of newly diagnosed tumors: glioblastoma $(A)$ and grade II oligodendroglioma (B). (Reprinted from (52).) 
uptake on ${ }^{18} \mathrm{~F}$-FDOPA PET scans. Four patients with radiation necrosis had low but visible ${ }^{18} \mathrm{~F}$-FDOPA uptake. Thus, ${ }^{18}$ F-FDOPA had a sensitivity of $96 \%$ and a specificity of $43 \%$, with an overall accuracy of $83 \%$ (95\% confidence interval, 70\%-97\%). The corresponding positive predictive value was $85 \%$, and the negative predictive value was $75 \%$.

With the same visual criterion, 14 of 23 tumors were visualized using ${ }^{18}$ F-FDG PET (sensitivity, 61\%). Similar to ${ }^{18} \mathrm{~F}$-FDOPA, ${ }^{18} \mathrm{~F}$-FDG showed no visible uptake in 3 stable patients in long-term remission and showed a low level of uptake in 4 patients with radiation necrosis (specificity, 43\%). Thus, ${ }^{18} \mathrm{~F}$-FDOPA was more sensitive overall than ${ }^{18} \mathrm{~F}-\mathrm{FDG}$ in identifying tumors. ${ }^{18} \mathrm{~F}$-FDOPA PET in gliomas demonstrated lower SUVs than did ${ }^{18}$ F-FDG. However, the contrast between tumor and normal tissue was higher than that with ${ }^{18} \mathrm{~F}-\mathrm{FDG}$ because of the low ${ }^{18} \mathrm{~F}$-FDOPA uptake in normal brain tissue. This higher contrast proved useful in detecting low-grade and recurrent tumors. For example, 8 of 9 recurrent tumors were negative for uptake on ${ }^{18} \mathrm{~F}-\mathrm{FDG}$ PET but positive on ${ }^{18}$ F-FDOPA PET (Fig. 7). Of these 9 patients, 5 had low-grade and 4 had high-grade tumor. If only high-grade tumors were considered, ${ }^{18} \mathrm{~F}-\mathrm{FDG}$ sensitivity would be $78 \%$ (14/18), rather than $61 \%$ (14/23), in detecting recurrent tumors, compared with $96 \%$ for ${ }^{18}$ F-FDOPA (22/ 23). ${ }^{18} \mathrm{~F}$-FDOPA may thus help to detect low-grade and recurrent tumors with greater sensitivity than ${ }^{18} \mathrm{~F}-\mathrm{FDG}$.

Standard visual analysis of ${ }^{18}$ F-FDOPA PET seemed adequate in that it provided a high sensitivity in identifying tumor. However, the specificity was low because all radiation necrosis lesions had low but visible tracer uptake.
Therefore, receiver-operating-characteristic analysis was used to identify the ${ }^{18}$ F-FDOPA uptake ratio for tumor to normal tissue that would give the best sensitivity and specificity: tumor to normal contralateral hemisphere $(\mathrm{T} / \mathrm{N})$, tumor to striatum $(\mathrm{T} / \mathrm{S})$, or tumor to white matter (T/W). The specificity of ${ }^{18} \mathrm{~F}$-FDOPA brain tumor imaging could be greatly increased by using a T/S threshold of 0.75 or 1.0 , a $\mathrm{T} / \mathrm{N}$ threshold of 1.3, or a T/W threshold of 1.6.

${ }^{18}$ F-FDOPA PET was subsequently expanded to a larger population of 51 patients to test these thresholds generated from receiver-operating-characteristic analysis of the first 30 patients studied (Table 2 ). Three patients had newly diagnosed gliomas ( 2 grade II and 1 grade III), and 47 patients were evaluated for recurrence (original primary tumors: 13 grade II, 13 grade III, and 21 grade IV). One newly identified lesion was subsequently found to be benign reactive changes. Thresholds of 0.75 or 1.0 for $\mathrm{T} / \mathrm{S}, 1.3$ for $\mathrm{T} / \mathrm{N}$, and 1.6 for T/W were used to test the sensitivity, specificity, positive predictive value, and negative predictive value (Table 3 ).

Although a T/S ratio of 0.75 resulted in a slightly higher accuracy of $95 \%$ and sensitivity of $98 \%$, a ratio of 1.0 provided slightly lower sensitivity, 92\%, but higher specificity, 95\% (Table 3). The latter ratio is clinically more practical because it does not require quantitative measurement, is visually more obvious, and is still highly accurate (accuracy of $93 \%$, with positive predictive value of $98 \%$ and negative predictive value of $80 \%$ ). The authors suggested using a T/S of 1.0 for first-line assessment and a T/S of 0.75 in inconclusive cases. In addition, one could use a $\mathrm{T} / \mathrm{S}$ of 1.0 when clinical suspicion of radiation necrosis is

A

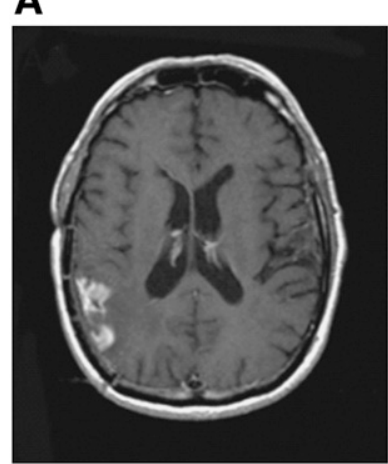

B

FIGURE 7. Use of MRI, ${ }^{18} \mathrm{~F}-\mathrm{FDG}$ PET, and ${ }^{18} \mathrm{~F}-\mathrm{FDOPA} \mathrm{PET}$ in evaluating recurrent tumors: glioblastoma $(A)$ and grade II oligodendroglioma (B). (Reprinted from (52).)

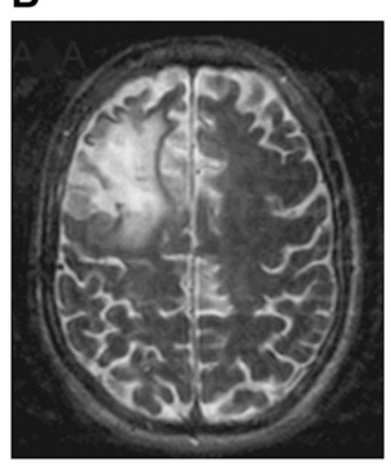

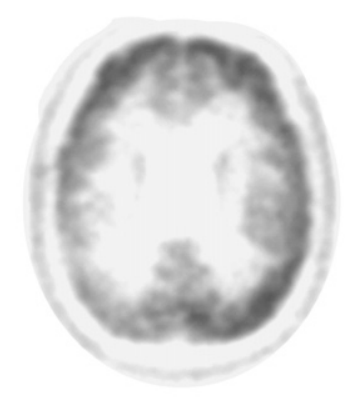
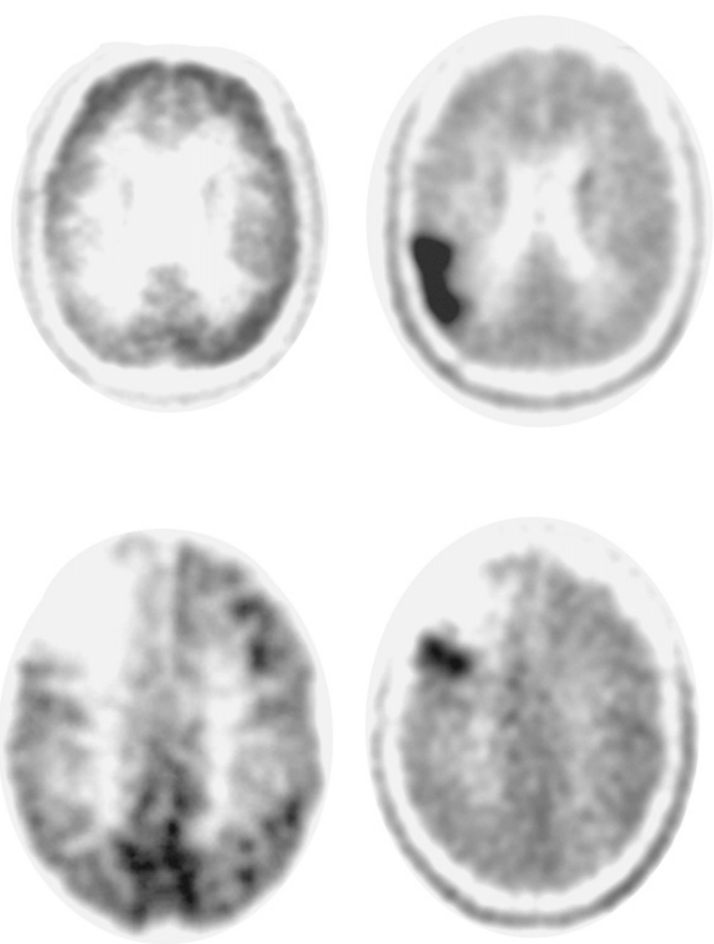
TABLE 2

Clinical Characteristics of Groups 1 and 2 for ${ }^{18} \mathrm{~F}-\mathrm{FDOPA}$ Study

\begin{tabular}{|c|c|c|c|}
\hline $\begin{array}{c}\text { Clinical } \\
\text { disease status }\end{array}$ & $\begin{array}{l}\text { Group 1 } \\
(n=30)\end{array}$ & $\begin{array}{l}\text { Group } 2 \\
(n=51)\end{array}$ & $\begin{array}{c}\text { Combining } 2 \\
\text { groups }(n=81)\end{array}$ \\
\hline \multicolumn{4}{|l|}{ Newly diagnosed patients } \\
\hline Grade II & 3 & 2 & 5 \\
\hline Grade III & 1 & 1 & 2 \\
\hline Grade IV & 3 & 0 & 3 \\
\hline Nontumor & 0 & 1 & 1 \\
\hline \multicolumn{4}{|l|}{ Clinically stable patients } \\
\hline Grade II & 2 & 6 & 8 \\
\hline Grade III & 1 & 7 & 8 \\
\hline Grade IV & 6 & 5 & 11 \\
\hline \multicolumn{4}{|l|}{ Posttreatment patients } \\
\hline Grade II & 1 & 4 & 5 \\
\hline Grade III & 2 & 1 & 3 \\
\hline Grade IV & 5 & 15 & 20 \\
\hline Posttreatment changes & 3 & 8 & 11 \\
\hline Long-term remission & 3 & 1 & 4 \\
\hline
\end{tabular}

higher and a T/S of 0.75 when clinical suspicion of recurrent tumor is higher.

Tumor grade did not significantly affect tracer uptake in 81 lesions in ${ }^{18} \mathrm{~F}$-FDOPA PET studies, a finding that is consistent with most studies using amino acid tracers (51-53). Likewise, no statistically significant difference in uptake levels was seen between contrast-enhancing tumors and nonenhancing tumors, in agreement with the notion that similar to tumor accumulation of other amino acid tracers, tumor accumulation of ${ }^{18} \mathrm{~F}$-FDOPA activity is most likely mediated through a specific transport system, rather than requiring breakdown of the BBB (56).

${ }^{18}$ F-FDOPA demonstrated excellent visualization of highand low-grade tumors and was more sensitive and specific than ${ }^{18} \mathrm{~F}-\mathrm{FDG}$ for evaluating recurrent tumors. ${ }^{18} \mathrm{~F}-\mathrm{FDOPA}$ may prove particularly valuable for examining recurrent lowgrade gliomas because these tumors are difficult to evaluate by MRI and are usually not visible on ${ }^{18}$ F-FDG PET. The study also suggested that ${ }^{18} \mathrm{~F}$-FDOPA might be valuable for distinguishing recurrent tumor from radiation necrosis, although a larger series of radiation necrosis cases is needed for confirmation.

\section{PET GUIDANCE OF DIAGNOSIS AND THERAPY}

\section{PET-Guided Biopsy}

Brain tumors are histologically heterogeneous. MRIguided stereotactic biopsy does not always yield a valid diagnosis or tumor grading, because some regions of the nonenhancing tumors may be high-grade. Accurate grading and diagnosis are especially important for directing the therapeutic approach and providing the prognosis in patients with nonresectable tumors. ${ }^{18}$ F-FDG PET-guided biopsy has previously been reported (80). Because amino acid
TABLE 3

Diagnostic Accuracy with ${ }^{18} \mathrm{~F}$-FDOPA PET Using Various Tumor-to-Normal-Tissue Thresholds in Groups 1 and 2

\begin{tabular}{lrcc}
\hline $\begin{array}{c}\text { Tumor-to-normal- } \\
\text { tissue threshold }\end{array}$ & $\begin{array}{c}\text { Group 1 } \\
(n=30)\end{array}$ & $\begin{array}{c}\text { Group 2 } \\
(n=51)\end{array}$ & $\begin{array}{c}\text { Combining 2 } \\
\text { groups }(n=81)\end{array}$ \\
\hline T/S $>0.75$ & & & \\
Sensitivity & 100 & 97 & 98 \\
Specificity & 86 & 86 & 86 \\
Accuracy & 97 & 94 & 95 \\
PPV & 96 & 95 & 95 \\
NPV & 100 & 92 & 95 \\
T/S $>1.0$ & & & \\
Sensitivity & 96 & 86 & 92 \\
Specificity & 100 & 93 & 95 \\
Accuracy & 97 & 88 & 93 \\
PPV & 100 & 94 & 98 \\
NPV & 88 & 75 & 80 \\
T/N > 1.3 & & & \\
Sensitivity & 96 & 95 & 95 \\
Specificity & 86 & 86 & 86 \\
Accuracy & 93 & 94 & 93 \\
PPV & 96 & 95 & 95 \\
NPV & 86 & 92 & 86 \\
T/W > 1.6 & & & \\
Sensitivity & 96 & 92 & 93 \\
Specificity & 86 & 86 & 86 \\
Accuracy & 93 & 84 & 91 \\
PPV & 96 & 87 & 95 \\
NPV & 86 & 75 & 82 \\
& & &
\end{tabular}

PPV $=$ positive predictive value; $\mathrm{NPV}=$ negative predictive value.

Adapted from (52). Data are percentages.

tracers have shown higher sensitivity in imaging tumors that, with ${ }^{18} \mathrm{~F}-\mathrm{FDG}$, are either hypo- or isometabolic to normal cortex, combining ${ }^{18} \mathrm{~F}-\mathrm{FDG}$ and an amino acid tracer for guidance of biopsy has been investigated.

The combination of ${ }^{18} \mathrm{~F}-\mathrm{FDG}$ and ${ }^{11} \mathrm{C}$-methionine for guidance of stereotactic biopsy was studied in 32 patients with unresectable gliomas (81). The double-tracer approach was proposed for these patients because they presented with a tumor considered unresectable and located in the cortical or subcortical gray matter-hence, likely of lower sensitivity on ${ }^{18} \mathrm{~F}$-FDG. PET images were coregistered with MRI and were analyzed to determine which tracer offered the best information for target definition. All 32 patients had histologically documented glioma: 10 glioblastomas, 12 anaplastic astrocytomas, and 10 low-grade gliomas. ${ }^{18} \mathrm{~F}-\mathrm{FDG}$ uptake was equal to or less than uptake in the surrounding gray matter in 18 patients, including 3 with glioblastoma, 6 with anaplastic astrocytoma, and 9 with low-grade glioma. ${ }^{18} \mathrm{~F}$ FDG was used for target selection when its uptake was higher in tumor than in gray matter (14 patients). ${ }^{11} \mathrm{C}$-Methionine was used for target selection when ${ }^{18} \mathrm{~F}-\mathrm{FDG}$ uptake was less than or equal to uptake in gray matter (18 patients). Sixtyone of the 70 stereotactic trajectories were based on PET-defined targets and showed abnormal ${ }^{11} \mathrm{C}$-methionine uptake. All $61{ }^{11} \mathrm{C}$-methionine-positive trajectories yielded 
a diagnosis of tumor. The remaining 9 trajectories were ${ }^{11} \mathrm{C}$ methionine-negative and nondiagnostic. The authors concluded from the study that because ${ }^{11} \mathrm{C}$-methionine provides a more sensitive signal, it is the tracer of choice for singletracer PET-guided neurosurgical procedures on gliomas.

The added value of ${ }^{18} \mathrm{~F}$-FET PET was investigated in 31 patients with suspected gliomas (82). PET and MRI were coregistered, and 52 neuronavigated tissue biopsies were taken from lesions with both an abnormal MRI signal and increased ${ }^{18} \mathrm{~F}$-FET uptake (match), as well as from areas with an abnormal MRI signal but normal ${ }^{18} \mathrm{~F}$-FET uptake or vice versa (mismatch). ${ }^{18} \mathrm{~F}$-FET findings were negative in 3 patients with an ischemic infarct and demyelinating disease, and these 3 patients were excluded from the study. Of the remaining 28 patients, tumor was diagnosed in 23 and reactive changes were found in the other 5 . The diagnostic performance of MRI alone was compared with that of MRI combined with ${ }^{18}$ F-FET. MRI yielded a sensitivity of $96 \%$ for the detection of tumor tissue but a specificity of $53 \%$. Combined use of MRI and ${ }^{18}$ F-FET PET yielded a sensitivity of $93 \%$ and a specificity of $94 \%$. Thus, the authors concluded that combined use of MRI and ${ }^{18}$ F-FET PET significantly improves the identification of tumor tissue.

The predictive value of ${ }^{18} \mathrm{~F}$-FET PET and MRI spectroscopy was compared in 50 patients with suspected diffused gliomas (83). Lesion-to-brain ratios greater than 1.6 for ${ }^{18}$ F-FET uptake were considered indicative of tumor. The results of MRI spectroscopy were considered positive when $\mathrm{N}$-acetylaspartate was decreased in conjunction with an absolute increase of choline and an $\mathrm{N}$-acetylaspartate-tocholine ratio of 0.7 or less. The diagnostic accuracy in distinguishing neoplastic from nonneoplastic tissue could be increased from $68 \%$ with the use of MRI alone to $97 \%$ with the use of MRI in conjunction with ${ }^{18} \mathrm{~F}$-FET PET and MRI spectroscopy. Sensitivity and specificity for tumor detection were $100 \%$ and $81 \%$, respectively, for MRI spectroscopy and $80 \%$ and $88 \%$, respectively, for ${ }^{18}$ F-FET PET. Histologic studies did not reveal tumor tissue in any lesions that were negative on ${ }^{18} \mathrm{~F}$-FET PET and MRI spectroscopy. Tumor was diagnosed for $97 \%$ of the lesions that were positive with both methods.

\section{PET-Guided Treatment}

Because PET activity reflects tumor metabolic activity, using PET to guide treatment seems to be a logical approach. Studies using PET to delineate tumor volumes for radiation therapy have been reported. In a study of 27 patients with glioblastoma, dose escalation using an ${ }^{18} \mathrm{~F}$ FDG PET-defined volume was investigated (84). Patients were treated initially with standard conformal fractionated radiotherapy with volumes defined by MRI. ${ }^{18} \mathrm{~F}-\mathrm{FDG}$ PET was performed after an initial dose of 45-50.4 Gy. Patients with tumors positive for ${ }^{18} \mathrm{~F}$-FDG PET uptake were treated with an additional $20 \mathrm{~Gy}$ to a total dose of $79.4 \mathrm{~Gy}$ based on volume as defined by ${ }^{18} \mathrm{~F}-\mathrm{FDG}$ uptake plus a $0.5-\mathrm{cm}$ margin. ${ }^{18} \mathrm{~F}$-FDG PET defined unique volumes for radiation dose escalation. Multivariate analysis demonstrated that ${ }^{18} \mathrm{~F}-\mathrm{FDG}$ PET uptake was the only parameter significant for predicting survival and time to tumor progression. However, in a subsequent report of 40 patients, such radiation dose escalation based on ${ }^{18} \mathrm{~F}$-FDG PET volume did not result in improved survival or time to tumor progression, compared with historical controls (85).

PET (or SPECT)/CT or PET (or SPECT)/MRI fusion with ${ }^{11} \mathrm{C}$-methionine and ${ }^{123} \mathrm{I}$-a-methyl-tyrosine was studied in 44 patients with recurrent glioblastoma after surgery and postoperative conventional radiotherapy (86). Fused imaging was used to delineate the volume in planning for fractional stereotactic radiotherapy. This volume was compared with the volume determined using CT or MRI alone. A significant survival advantage was found: a 9-mo median survival in patients whose treatment volume was based on fused imaging, versus a 5-mo median survival in patients whose treatment planning was based on CT or MRI alone. ${ }^{11} \mathrm{C}$-Methionine was also used with $\mathrm{CT}$ or MRI to delineate the target volume in patients with meningiomas (87). Information from ${ }^{11} \mathrm{C}$-methionine was found useful for determining gross tumor volume.

\section{OTHER PET TRACERS AND FUTURE DIRECTIONS ${ }^{18}$ F-FLT PET}

The thymidine analog $3^{\prime}$-deoxy- $3^{\prime}-{ }^{18} \mathrm{~F}$-fluorothymidine (FLT) PET was developed as a noninvasive method to evaluate tumor cell proliferation (88). Uptake of ${ }^{18} \mathrm{~F}$-FLT correlates with thymidine kinase-1 activity, an enzyme expressed during the DNA synthesis phase of the cell cycle (89). Thymidine kinase-1 activity is high in proliferating cells and low in quiescent cells. Phosphorylation of ${ }^{18} \mathrm{~F}-$ FLT intracellularly by thymidine kinase-1 results in trapping of the negatively charged ${ }^{18} \mathrm{~F}$-FLT monophosphate $(90,91)$. Although ${ }^{18}$ F-FLT appears to have limited sensitivity, uptake of ${ }^{18}$ F-FLT by tumors correlates with Ki-67, a common proliferation index used ex vivo, as demonstrated in several extracranial cancers (92-96). ${ }^{18}$ F-FLT uptake has also been investigated in brain tumors, and similar correlations have been observed (97-102). Thus, ${ }^{18}$ F-FLT has the potential to monitor treatment response and to serve as a prognostic marker.

\section{${ }^{18}$ F-Fluoromisonidazole PET}

${ }^{18}$ F-Fluoromisonidazole is a nitroimidazole derivative that has been developed as a PET agent to image hypoxia (103). Metabolites of ${ }^{18} \mathrm{~F}$-fluoromisonidazole are trapped exclusively in hypoxic cells (104). Hypoxia in tumors is a pathophysiologic consequence of structurally and functionally disturbed angiogenesis along with deterioration of the ability of oxygen to diffuse through tissues. Hypoxia is associated with tumor progression and resistance to radiotherapy (105). Investigation of brain tumors with ${ }^{18} \mathrm{~F}$-fluoromisonidazole PET demonstrated a correlation with perfusion at 0-5 min after injection, whereas late images at 150-170 min after injection were independent of perfusion and $\mathrm{BBB}$ disruption 
(106). ${ }^{18}$ F-Fluoromisonidazole uptake was found in highgrade gliomas but not in low-grade gliomas, and a significant relationship was found between ${ }^{18} \mathrm{~F}$-fluoromisonidazole uptake and expression of the angiogenesis marker VEGF-R1 (107). Thus ${ }^{18} \mathrm{~F}$-fluoromisonidazole may have a role in directing and monitoring targeted hypoxic therapy.

\section{${ }^{68}$ Ga-DOTA-TOC}

The somatostatin analog ${ }^{68} \mathrm{Ga}$-DOTA-D-Phe ${ }^{1}$-Tyr ${ }^{3}$-octreotide (DOTA-TOC) was investigated in meningiomas, because they show high expression of the somatostatin receptor subtype 2 . In contrast to ${ }^{18} \mathrm{~F}-\mathrm{FDG},{ }^{68} \mathrm{Ga}$-DOTA-TOC showed a high meningioma-to-background ratio (108) and added valuable information on the extent of meningiomas beneath osseous structures, especially at the skull base. Further, kinetic studies showed that high uptake of ${ }^{68} \mathrm{Ga}$-DOTA-TOC in meningiomas can be explained by the high value for vascular fraction and markedly low values for $\mathrm{k} 2$ and $\mathrm{k} 4$, leading to significantly greater $\mathrm{k} 1 / \mathrm{k} 2$ and $\mathrm{k} 3 / \mathrm{k} 4$ ratios and receptor binding in meningiomas than in reference tissue (109).

\section{SUMMARY}

Although MRI remains the gold standard for the diagnosis and follow-up of malignant brain tumors, ${ }^{18} \mathrm{~F}-\mathrm{FDG}$ PET has a potential role in providing prognostic information. In previously treated patients, ${ }^{18}$ F-FDG PET can be helpful in differentiating recurrent tumor from radiation necrosis. It is critical to have the MRI information available while ${ }^{18} \mathrm{~F}-\mathrm{FDG}$ PET studies are interpreted. Delayed ${ }^{18} \mathrm{~F}-$ FDG PET may increase diagnostic accuracy.

Amino acid tracers are promising in that they are more sensitive in imaging brain tumors. Amino acid tracers may also be useful in distinguishing recurrent tumors from radiation necrosis, although further studies are needed.

The use of PET to plan and monitor treatment is an active area of investigation. With the development of targeted therapies, PET biomarkers might be used to select patients who are likely to respond to treatment, as well as to monitor treatment response. Patients who do not respond to a particular treatment can avoid unnecessary toxicity and be switched to a different, potentially more efficacious, regimen earlier on.

\section{ACKNOWLEDGMENTS}

This study was supported by grant P50 CA086306 from the National Cancer Institute, National Institute of Health, and by contract DE-FC03-87-ER60615 from the U.S Department of Energy.

\section{REFERENCES}

1. Jemal A, Murray T, Ward E, et al. Cancer statistics. CA Cancer J Clin. 2005; 55:10-30.

2. Kleihues P, Cavenee WK, eds. World Health Organization Classification of Tumours: Pathology and Genetics-Tumours of the Nervous System. New York, NY: Oxford University Press; 2000.
3. Posner JB. Neurologic Complications of Cancer. Philadelphia, PA: E.A. Davis; 1995.

4. Central Brain Tumor Registry of the United States, 2005-2006. Available at: http://www.cbtrus.org. Accessed July 25, 2007.

5. Ohgaki H, Kleihues P. Population-based studies on incidence, survival rates, and genetic alterations in astrocytic and oligodendroglial gliomas. J Neuropathol Exp Neurol. 2005;64:479-489.

6. Hess KR. Extent of resection as a prognostic variable in the treatment of gliomas. J Neurooncol. 1999;42:227-231.

7. Simpson JR, Horton J, Scott C, et al. Influence of location and extent of surgical resection on survival of patients with glioblastoma multiforme: results of three consecutive Radiation Therapy Oncology Group (RTOG) clinical trials. Int J Radiat Oncol Biol Phys. 1993;26:239-244.

8. Fadul C, Wood J, Thaler H, et al. Morbidity and mortality of craniotomy for excision of supratentorial gliomas. Neurology. 1988;38:1374-1379.

9. Walker MD, Strike TA, Sheline GE. An analysis of dose effect relationship in the radiotherapy of malignant gliomas. Int J Radiat Oncol Biol Phys. 1979;5: 1725-1731.

10. Walker MD, Alexander E Jr, Hunt WE, et al. Evaluation of BCNU and/or radiotherapy in the treatment of anaplastic gliomas: a cooperative clinical trial. J Neurosurg. 1978;49:333-343.

11. Mahaley MS Jr, Mettlin C, Natarajan N, Laws ER Jr., Peace BB. National survey of patterns of care for brain tumor patients. J Neurosurg. 1989;71:826-836.

12. Stewart LA. Chemotherapy in adult high-grade glioma: a systematic review and meta-analysis of individual patient data from 12 randomized trials. Lancet. 2002;359:1011-1018.

13. Stupp R, Mason WP, van den Bent MJ, et al. Radiotherapy plus concomitant and adjuvant temozolomide for glioblastoma. N Engl J Med. 2005;352:987-996.

14. Athanassiou H, Svnodinou M, Maragoudakis E, et al. Randomized phase II study of temozolomide and radiotherapy compared with radiotherapy alone in newly diagnosed glioblastoma multiforme. J Clin Oncol. 2005;23:2372-2377.

15. Levivier M, Becerra A, De Witte O, et al. Radiation necrosis or recurrence. J Neurosurg. 1996;84:148-149.

16. Grant R, Liang BC, Slattery J, et al. Chemotherapy response criteria in malignant glioma. Neurology. 1997;48:1336-1340.

17. Burkhard C, Di Patre PL, Schuler D, et al. A population-based study on the incidence and survival of patients with pilocytic astrocytoma. J Neurosurg. 2003;98:1170-1174.

18. Lang FF, Gilbert MR. Diffusely infiltrative low-grade gliomas in adults. J Clin Oncol. 2006;24:1236-1245.

19. Cavaliere R, Beatriz SL, Schiff D. Low-grade gliomas: an update on pathology and therapy. Lancet Neurol. 2005;4:760-770.

20. Leighton C, Fisher B, Bauman G, et al. Supratentorial low-grade glioma in adults: an analysis of prognostic factors and timing of radiation. J Clin Oncol. 1997; 15:1294-1301.

21. Olson JD, Riedel E, DeAngelis LM. Long-term outcome of low-grade oligodendroglioma and mixed glioma. Neurology. 2000;54:1442-1448.

22. Jackson R, Fuller G, Abi-Said D, et al. Limitations of stereotactic biopsy in the initial management of gliomas. Neurooncol. 2001;3:193-200.

23. Keles GE, Aldape K, Berger MS. Low-grade gliomas: astrocytoma, oligodendroglioma, and mixed gliomas. In: Winn HR, ed.: Houmans Neurological Surgery. 5th ed. Philadelphia, PA: W.B. Saunders Co.; 2004:950-968.

24. van den Bent MJ, Afra D, de Witte O, et al. Long-term efficacy of early versus delayed radiotherapy for low-grade astrocytoma and oligodendroglioma in adults: the EORTC 22845 randomized trial. Lancet. 2005;366:985-990.

25. Pignatti F, van de Bent M, Curran D, et al. Prognostic factors for survival in adult patients with cerebral low-grade glioma. J Clin Oncol. 2002;20:20762084.

26. Stege EM, Kros JM, de Bruin HG, et al. Successful treatment of low-grade oligodendroglioma tumors with a chemotherapy regimen of procarbazine, lomustine, and vincristine. Cancer. 2005;103:802-809.

27. Feifenberger G, Kros JM, Burger PC. Oligodendrogliomas. In: Kleihues P, Cavenee WK, eds. World Health Organization Classification of Tumours: Pathology and Genetics-Tumours of the Nervous System. New York, NY: Oxford University Press; 2000.56-61.

28. CBTRUS. Statistical Report: Primary Brain Tumors in the United States, 1995 1999. Chicago, IL: Central Brain Tumor registry of the United States; 2002.

29. Cavaliere R, Schiff D. Cerebral metastases: a therapeutic update. Nat Clin Pract Neurol. 2006;2:426-436.

30. Patchell RA, Tibbs PA, Walsh JW, et al. A randomized trial of surgery in the treatment of single metastases to the brain. N Engl J Med. 1990;322:494-500.

31. Vecht CJ, Haaxma-Reiche H, Noordijk EM, et al. Treatment of single brain metastasis: radiotherapy alone or combined with neurosurgery? Ann Neurol. 1993;33:583-590. 
32. Del Sole A, Falini A, Ravasi L, et al. Anatomical and biochemical investigation of primary brain tumours. Eur J Nucl Med. 2001;28:1851-1872.

33. Watling CJ, Lee DH, Macdonald DR, et al. Corticosteroid-induced magnetic resonance imaging changes in patients with recurrent malignant glioma. $J$ Clin Oncol. 1994;12:1886-1889.

34. Patronas NJ, Di Chiro G, Brooks RA, et al. Work in progress: $\left[{ }^{18} \mathrm{~F}\right]$ fluorodeoxyglucose and positron emission tomography in the evaluation of radiation necrosis of the brain. Radiology. 1982;144:885-889.

35. Di Chiro G, Oldfield E, Wright DC, et al. Cerebral necrosis after radiotherapy and/or intraarterial chemotherapy for brain tumors: PET and neuropathologic studies. AJR. 1988;150:189-197.

36. Wong TZ, van der Westhuizen GJ, Coleman RE. Positron emission tomography imaging of brain tumors. Neuroimaging Clin N Am. 2002;12:615-626.

37. Padoma MV, Said S, Jacobs M, et al. Prediction of pathology and survival by FDG PET in gliomas. J Neurooncology. 2003;64:227-237.

38. De Witte O, Levivier M, Violon P, et al. Prognostic value of positron emission tomography with $\left[{ }^{18} \mathrm{~F}\right]$ fluoro-2-D-glucose in the low-grade glioma. J Neurosurg. 1996;39:470-477.

39. Olivero WC, Dulebohn SC, Lister JR. The use of PET in evaluating patients with primary brain tumors: is it useful? J Neurol Neurosurg Psychiatry. 1995; $58: 250-252$.

40. Ricci PE, Karis JP, Heiserman JE, et al. Differentiating recurrent tumor from radiation necrosis: time for re-evaluation of positron emission tomography? Am J Neuroradiol. 1998;19:407-413.

41. Krohn KA, Mankoff DA, Muzi M, et al. True tracers: comparing FDG with glucose and FLT with thymidine. Nucl Med Biol. 2005;32:663-671.

42. Wong TZ, Turkington TG, Hawk TC, et al. PET and brain tumor image fusion. Cancer J. 2004;10:234-242.

43. Ishizu K, Sadato N, Yonekura Y, et al. Enhanced detection of brain tumors by $\left[{ }^{18} \mathrm{~F}\right]$ fluorodeoxyglucose PET with glucose loading. J Comput Assist Tomogr. 1994;18:12-15

44. Spence AM, Muzi M, Mankoff DA, et al. ${ }^{18}$ F-FDG PET of gliomas at delayed intervals: improved distinction between tumor and normal gray matter. $\mathrm{J} \mathrm{Nucl}$ Med. 2004;45:1653-1659.

45. Ishiwata K, Kutota K, Murakami M, et al. Re-evaluation of amino acid PET studies: can the protein synthesis rates in brain and tumor tissues be measured in vivo? J Nucl Med. 1993;34:1936-1943.

46. Jager PL, Vaalburg W, Pruim J, et al. Radiolabeled amino acids: basic aspects and clinical applications in oncology. $J$ Nucl Med. 2001;42:432-445.

47. Herholz K, Holzer T, Bauer B, et al. ${ }^{11} \mathrm{C}-$ Methionine PET for differential diagnosis of low-grade gliomas. Neurology. 1998;50:1316-1322.

48. Laverman P, Boerman OC, Corstens FH, Oyen WJ. Fluorinated amino acids for tumour imaging with positron emission tomography. Eur J Nucl Med Mol Imaging. 2002;29:681-690.

49. Weber WA, Wester HJ, Grosu AL, et al. $O-\left(2-\left[{ }^{18} \mathrm{~F}\right]\right.$ fluoroethyl $)-\mathrm{L}-$ tyrosine and L-[methyl- $\left.{ }^{11} \mathrm{C}\right]$ methionine uptake in brain tumours: initial results of a comparative study. Eur J Nucl Med. 2000;27:542-549.

50. Becherer A, Karanikas G, Szabo M, et al. Brain tumour imaging with PET: a comparison between $\left[{ }^{18} \mathrm{~F}\right]$ fluorodopa and $\left[{ }^{11} \mathrm{C}\right]$ methionine. Eur J Nucl Med Mol Imaging. 2003;30:1561-1567.

51. Beuthien-Baumann B, Bredow J, Burchert W, et al. 3-O-Methyl-6- $\left[{ }^{18} \mathrm{~F}\right]$ fluoroL-DOPA and its evaluation in brain tumour imaging. Eur J Nucl Med Mol Imaging. 2003;30:1004-1008.

52. Chen W, Silverman DHS, Delaloye S, et al. ${ }^{18} \mathrm{~F}$-FDOPA PET imaging of brain tumors: comparison study with ${ }^{18} \mathrm{~F}-\mathrm{FDG}$ PET and evaluation of diagnostic accuracy. J Nucl Med. 2006;47:904-911.

53. Jager PL, Vaalburg W, Prium J, et al. Radiolabeled amino acids: basic aspects and clinical applications in oncology. $J$ Nucl Med. 2001;42:432-445.

54. Isselbacher KJ. Sugar and amino acid transport by cells in culture: differences between normal and malignant cells. N Engl J Med. 1972;286:929-933.

55. Busch H, Davis JR, Honig GR, et al. The uptakes of a variety of amino acids into nuclear proteins of tumors and other tissues. Cancer Res. 1959;19:1030-1039.

56. Miyagawa T, Oku T, Uehara H, et al. "Facilitated" amino acid transport is upregulated in brain tumors. J Cereb Blood Flow Metab. 1998;18:500-509.

57. Sasajima T, Miyagawa T, Oku T, et al. Proliferation-dependent changes in amino acid transport and glucose metabolism in glioma cell lines. Eur J Nucl Med Mol Imaging. 2004;31:1244-1256.

58. Roelcke U, Radu EW, von Ammon K, Hausmann O, Maguire RP, Leenders $\mathrm{KL}$. Alteration of blood-brain barrier in human brain tumors: comparison of $\left[{ }^{18} \mathrm{~F}\right]$ fluorodeoxyglucose, $\left[{ }^{11} \mathrm{C}\right]$ methionine and rubidium-82 using PET. J Neurol Sci. 1995;132:20-27.

59. Bergmann R, Pietzsch J, Fuechtner F, et al. 3-O-Methyl-6- ${ }^{18}$ F-fluoro-L-dopa, a new tumor imaging agent: investigation of transport mechanism in vitro. $J \mathrm{Nucl}$ Med. 2004;45:2116-2122.
60. Hustinx R, Pourdehnad M, Kaschten B, et al. PET imaging for differentiating recurrent brain tumor from radiation necrosis. Radiol Clin North Am. 2005;43: 35-47.

61. Giglio P, Gilbert HR. Cerebral radiation necrosis. Neurologist. 2003;9: $180-188$.

62. Langleben DD, Segall GM. PET in differentiation of recurrent brain tumor from radiation injury. $J$ Nucl Med. 2000;41:1861-1867.

63. Hustinx R, Smith RJ, Benard F, et al. Can the standardized uptake value characterize primary brain tumors on FDG-PET? Eur J Nucl Med. 1999;26: 1501-1509.

64. Henze M, Mohammed A, Schlemmer HP, et al. PET and SPECT for detection of tumor progression in irradiated low-grade astrocytoma: a receiver-operatingcharacteristic analysis. J Nucl Med. 2004;45:579-586.

65. Chao ST, Suh JH, Raja S, et al. The sensitivity and specificity of FDG PET in distinguishing recurrent brain tumors from radionecrosis in patients treated with stereotactic radiosurgery. Int J Cancer. 2001;96:191-197.

66. Wang SX, Boethius J, Ericson K. FDG-PET on irradiated brain tumor: ten years' summary. Acta Radiol. 2006;47:85-90.

67. Spence A, Mankoff DA, Muzi M. Positron emission tomography imaging of brain tumors. Neuroimaging Clin N Am. 2003;13:717-739.

68. Tsuyuguchi N, Sunada I, Iwai Y, et al. Methionine positron emission tomography of recurrent metastatic brain tumor and radiation necrosis after stereotactic radiosurgery: is a differential diagnosis possible? J Neurosurg. 2003;98:1056-1064.

69. Spaeth N, Wyss MT, Weber B, et al. Uptake of ${ }^{18} \mathrm{~F}$-fluorocholine, ${ }^{18} \mathrm{~F}$ fluoroehtyl-L-tyrosine, and ${ }^{18} \mathrm{~F}-\mathrm{FDG}$ in acute cerebral radiation injury in the rat: implications for separation of radiation necrosis from tumor recurrence. J Nucl Med. 2004;45:1931-1938.

70. Chung JK, Kim YK, Kim SK, et al. Usefulness of ${ }^{11} \mathrm{C}$-methionine PET in the evaluation of brain lesions that are hypo- or isometabolic on ${ }^{18} \mathrm{~F}-\mathrm{FDG}$ PET. Eur J Nucl Med Mol Imaging. 2002;29:176-182.

71. Popperl G, Gotz C, Rachinger W, et al. Value of $O$-(2-[ $\left.{ }^{18} \mathrm{~F}\right]$ fluoroethyl)-Ltyrosine PET for the diagnosis of recurrent glioma. Eur J Nucl Med Mol Imaging. 2004;31:1464-1470.

72. Rachinger W, Goetz C, Popperl G, et al. Positron emission tomography with $O-\left(2-\left[{ }^{18} \mathrm{~F}\right]\right.$ fluoroethyl $)-\mathrm{L}$-tyrosine versus magnetic resonance imaging in the diagnosis of recurrent gliomas. Neurosurgery. 2005;57:505-511.

73. Weckesser M, Langen KJ, Rickert $\mathrm{CH}$, et al. $O$-[2-[ $\left[{ }^{18} \mathrm{~F}\right]$ fluoroethyl)-L-tyrosine PET in the clinical evaluation of primary brain tumors. Eur J Nucl Med Mol Imaging. 2005;32:422-429.

74. Garnett S, Firnau G, Nahmias C, Chirakal R. Striatal dopamine metabolism in living monkeys examined by positron emission tomography. Brain Res. 1983; 280:169-171.

75. Garnett ES, Firnau G, Nahmias C. Dopamine visualized in the basal ganglia of living man. Nature. 1983;305:137-138.

76. Herholz K, Heiss WD. Positron emission tomography in clinical neurology. Mol Imaging Biol. 2004;6:239-269.

77. Yee RE, Cheng DW, Huang SC, et al. Blood-brain barrier and neuronal membrane transport of 6-[ ${ }^{18}$ F]fluoro-L-DOPA. Biochem Pharmacol. 2001;62: 1409-1415.

78. Stout DB, Huang SC, Melega WP, et al. Effects of large neutral amino acid concentrations on 6-[F-18]fluoro-L-DOPA kinetics. J Cereb Blood Flow Metab. 1998; 18:43-51

79. Heiss WD, Wienhard K, Wagner R, et al. F-Dopa as an amino acid tracer to detect brain tumors. J Nucl Med. 1996;37:1180-1182.

80. Levivier M, Goldman S, Pirotte B, et al. Diagnostic yield of stereotactic brain biopsy guided by positron emission tomography with $\left[{ }^{18} \mathrm{~F}\right]$ fluorodeoxyglucose. J Neurosurg. 1995;82:445-452.

81. Pirotte B, Goldman S, Massager N, et al. Combined use of ${ }^{18} \mathrm{~F}$-fluorodeoxyglucose and ${ }^{11} \mathrm{C}$-methionine in 45 positron emission tomography-guided stereotactic brain biopsies. J Nucl Med. 2004;45:1293-1298.

82. Pauleit D, Floeth F, Hamacher K, et al. $O-\left(2-\left[{ }^{18} \mathrm{~F}\right]\right.$ fluoroethyl $)-\mathrm{L}$-tyrosine PET combined with MRI improves the diagnostic assessment of cerebral gliomas. Brain. 2005;128:678-687.

83. Floeth FW, Pauleit D, Wittsack HJ, et al. Multimodal metabolic imaging of cerebral gliomas: positron emission tomography with $\left[{ }^{18} \mathrm{~F}\right]$ fluoroethyl-Ltyrosine and magnetic resonance spectroscopy. J Neurosurg. 2005;102:318327.

84. Tralins KS, Douglas JG, Stelzer KJ, et al. Volumetric analysis of ${ }^{18}$ F-FDG PET in glioblastoma multiforme: prognostic information and possible role in definition of target volumes in radiation dose escalation. J Nucl Med. 2002;43: 1667-1673.

85. Douglas JG, Stelzer KJ, Mankoff DA, et al. [F-18]-Fluorodeoxyglucose positron emission tomography for targeting radiation dose escalation for 
patients with glioblastoma multiforme: clinical outcomes and patterns of failure. Int J Radiat Oncol Biol Phys. 2006;64:886-891.

86. Grosu AL, Weber WA, Franz M, et al. Reirradiation of recurrent high-grade gliomas using amino acid PET (SPECT)/CT/MRI image fusion to determine gross tumor volume for stereotactic fractional radiotherapy. Int J Radiat Oncol Biol Phys. 2005;63:511-519.

87. Grosu AL, Weber WA, Asther ST, et al. ${ }^{11} \mathrm{C}-$ Methionine PET improves the target volume delineation of meningiomas treated with stereotactic fractionated radiotherapy. Int J Radiat Oncol Biol Phys. 2006;66:339-344.

88. Shields A, Grierson J, Dohmen B, et al. Imaging proliferation in vivo with F-18 FLT and positron emission tomography. Nat Med. 1998;4:1334-1336.

89. Rasey JS, Grierson JR, Wiens LW, Kolb PD, Schwartz JL. Validation of FLT uptake as a measure of thymidine kinase-1 activity in A549 carcinoma cells. J Nucl Med. 2002;43:1210-1217.

90. Toyohara J, Waki A, Takamatsu S, et al. Basis of FLT as a cell proliferation marker: comparative uptake studies with $\left[{ }^{3} \mathrm{H}\right]$ thymidine and $\left[{ }^{3} \mathrm{H}\right]$ arabinothymidine, and cell-analysis in 22 asynchronously growing tumor cell lines. Nucl Med Biol. 2002;29:281-287.

91. Schwartz JL, Grierson JR, Rasey JS, Wiens L, Jordan R, Kohli T. Rates of accumulation and retention of 3-deoxy-3-fluorothymidine (FLT) in different cell lines [abstract]. J Nucl Med. 2001;42(suppl):283P.

92. Buck AK, Halter G, Schirrmeister H, et al. Imaging proliferation in lung tumors with PET: ${ }^{18}$ F-FLT versus ${ }^{18}$ F-FDG. J Nucl Med. 2003;44:1426-1431.

93. Yap CS, Czernin J, Fishbein MC, et al. Evaluation of thoracic tumors with ${ }^{18} \mathrm{~F}-$ fluorothymidine and ${ }^{18} \mathrm{~F}$-fluorodeoxyglucose positron emission tomography. Chest. 2006;129:393-401.

94. Vesselle H, Grierson J, Muzi M, et al. In vivo validation of 3'deoxy-3'$\left[{ }^{18} \mathrm{~F}\right]$ fluorothymidine $\left(\left[{ }^{18} \mathrm{~F}\right] \mathrm{FLT}\right)$ as a proliferation imaging tracer in humans: correlation of $\left[{ }^{18} \mathrm{~F}\right] \mathrm{FLT}$ uptake by positron emission tomography with $\mathrm{Ki}-67$ immunohistochemistry and flow cytometry in human lung tumors. Clin Cancer Res. 2002;8:3315-3332.

95. Francis DL, Freeman A, Visvikis D, et al. In vivo imaging of cellular proliferation in colorectal cancer using positron emission tomography. Gut. 2003;52: 1602-1606.

96. Wagner M, Seitz U, Buck A, et al. $3^{\prime}\left[{ }^{18} \mathrm{~F}\right]$ Fluoro- $3^{\prime}$-deoxythymidine $\left(\left[{ }^{18} \mathrm{~F}\right] \mathrm{FLT}\right)$ as positron emission tomography tracer for imaging proliferation in a murine B-cell lymphoma model and in the human disease. Cancer Res. 2003;63:2681-2687.
97. Buck AK, Bommer M, Stilgenbauer S, et al. Molecular imaging of proliferation in malignant lymphoma. Cancer Res. 2006;66:11055-11061.

98. Chen W, Cloughesy T, Kamdar N, et al. Imaging proliferation in brain tumors with ${ }^{18}$ F-FLT PET: comparison with FDG. J Nucl Med. 2005;46:945-952.

99. Jacobs AH, Thomas A, Kracht LW, et al. ${ }^{18} \mathrm{~F}-$ Fluoro-L-thymidine and ${ }^{11} \mathrm{C}$ methymethione as markers of increased transport and proliferation in brain tumors. J Nucl Med. 2005;46:1948-1958.

100. Yamamoto Y, Wong TZ, Turkington TC, et al. 3'-Deoxy-3'-[F-18]fluorothymidine positron emission tomography in patients with recurrent glioblastoma multiforme: comparison with Gd-DTPA enhanced magnetic resonance imaging. Mol Imaging Biol. 2006;8:340-347.

101. Choi SJ, Kim JS, Kim JH, et al. $\left[{ }^{18} \mathrm{~F}\right] 3^{\prime}$-Deoxy-3'-fluorothymidine PET for the diagnosis and grading of brain tumors. Eur J Nucl Med Mol Imaging. 2005;32: 653-659.

102. Saga T, Kawashima H, Araki N, et al: Evaluation of primary brain tumors with FLT-PET: usefulness and limitations. Clin Nucl Med 2006;31:774-780.

103. Rasey JS, Koh WJ, Evans ML, et al. Quantifying regional hypoxia in human tumors with positron emission tomography of $\left[{ }^{18} \mathrm{~F}\right]$ fluoromisonidazole: a pretherapy study of 37 patients. Int J Radiat Oncol Biol Phys. 1996;36:417-428.

104. Whitmore GF, Varghese AJ. The biological properties of reduced nitroheterocyclics and possible underlying biochemical mechanisms. Biochem Pharmacol. 1986;35:97-103.

105. Brown JM. Therapeutic targets in radiotherapy. Int J Radiat Oncol Biol Phys. 2001;49:319-326.

106. Bruehlmeier M, Roelcke U, Schubiger PA, Ametamey SM. Assessment of hypoxia and perfusion in human brain tumors using PET with ${ }^{18} \mathrm{~F}$ fluoromizonidazole and ${ }^{15} \mathrm{O}-\mathrm{H}_{2} \mathrm{O}$. J Nucl Med. 2004;45:1851-1859.

107. Cher LM, Murone C, Lawrentschuk N, et al. Correlation of hypoxic cell fraction and angiogenesis with glucose metabolic rate in gliomas using ${ }^{18} \mathrm{~F}$ fluoromisonidazole, ${ }^{18}$ F-FDG PET, and immunohistochemical studies. $\mathrm{J} \mathrm{Nucl}$ Med. 2006;47:410-418.

108. Henze M, Schuhmacher J, Hipp P, et al. PET imaging of somatostatin receptors using $\left[{ }^{68} \mathrm{Ga}\right]$ DOTA-D-Phe ${ }^{1}-\mathrm{Tyr}^{3}$-octreotide: first results in patients with meningiomas. J Nucl Med. 2001;42:1053-1056.

109. Henze M, Dimitrakopoulou-Strauss A, Milker-Zabel S, et al. Characterization of ${ }^{68} \mathrm{Ga}$-DOTA-D-Phe ${ }^{1}$-Tyr ${ }^{3}$-octreotide kinetics in patients with meningiomas. J Nucl Med. 2005;46:763-769. 